\title{
A Time to Remember: The Role of Circadian Clocks in Learning and Memory
}

\author{
Benjamin L. Smarr, Kimberly J. Jennings, Joseph R. Driscoll, and Lance J. Kriegsfeld \\ University of California, Berkeley
}

\begin{abstract}
The circadian system has pronounced influence on learning and memory, manifesting as marked changes in memory acquisition and recall across the day. From a mechanistic perspective, the majority of studies have investigated mammalian hippocampal-dependent learning and memory, as this system is highly tractable. The hippocampus plays a major role in learning and memory, and has the potential to integrate circadian information in many ways, including information from local, independent oscillators, and through circadian modulation of neurogenesis, synaptic remodeling, intracellular cascades, and epigenetic regulation of gene expression. These local processes are combined with input from other oscillatory systems to synergistically augment hippocampal rhythmic function. This overview presents an account of the current state of knowledge on circadian interactions with learning and memory circuitry and provides a framework for those interested in further exploring these interactions.
\end{abstract}

Keywords: daily, recall, hormones, neurogenesis, hippocampus

To appropriately coordinate behavior and physiology with daily changes in their ecosystem, animals utilize an endogenous circadian timing system (Sharma, 2003). By employing an internal timing system, animals can anticipate environmental change and prepare accordingly, rather than respond only after the fact to a given event (Antle \& Silver, 2009). Such an internal timing system should allow the formation of associations between a given stimulus with circadian phase, so that predictable daily events, or shifts thereof (i.e., changes following migration or alteration of temporal niche), can be accommodated (Daan, 2000; Smarr, Schwartz, Wotus, \& de la Iglesia, 2013). Given the extent of physiological modulation by the circadian system, it not surprising that the ability to make these associations varies across the day.

Although the present overview focuses on mammals, the ability to phase behavior with appropriate times of day is common across taxa. For example, honey bees (Apis mellifera) can learn to use different floral landing strategies when collecting pollen based on time of day and associated changes in blossom position (J. L. Gould, 1987). Fish can be trained to swim to different sides of an aquarium for evening versus morning meals (Reebs, 1996). Garden warblers (Sylvia borin) learn to forage in different locations at different times of day based on daily rhythms in food availability

This article was published Online First April 7, 2014.

Benjamin L. Smarr and Kimberly J. Jennings, Department of Psychology, University of California, Berkeley; Joseph R. Driscoll, The Helen Wills Neuroscience Institute, University of California, Berkeley; Lance J. Kriegsfeld, Department of Psychology and The Helen Wills Neuroscience Institute, University of California, Berkeley.

Support during the writing of this review was received from National Institutes of Health Grant R01 HD050470.

Correspondence concerning this article should be addressed to Lance J. Kriegsfeld, Neurobiology Laboratory, Department of Psychology and Helen Wills Neuroscience Institute, 3210 Tolman Hall, \#1650, University of California, Berkeley, CA 94720-1650. E-mail: Kriegsfeld@berkeley.edu
(Biebach, Falk, \& Krebs, 1991). Finally, rodents rapidly learn food (Bolles \& Stokes, 1965; Carr \& Wilkie, 1997; Holmes \& Mistlberger, 2000; Marchant \& Mistlberger, 1997; Mistlberger, de Groot, Bossert, \& Marchant, 1996; Mistlberger, 1993) and water (Mistlberger, 1992, 1993) spatial associations specific to time of day (Cain, Chou, \& Ralph, 2004; Cain, McDonald, \& Ralph, 2008; Carr \& Wilkie, 1997; Holloway \& Wansley, 1973a, 1973b; Hunsicker \& Mellgren, 1977; Ko, McDonald, \& Ralph, 2003; Mistlberger et al., 1996; Ralph et al., 2002; Stephan \& Kovacevic, 1978; Wansley \& Holloway, 1975). Pairings of specific spaces with specific times can be learned through associations with both positive (Carr \& Wilkie, 1997; Hunsicker \& Mellgren, 1977; Ko et al., 2003; Mistlberger et al., 1996; Ralph et al., 2002; Wansley \& Holloway, 1975) and negative (Cain, Chou, et al., 2004; Cain et al., 2008; Holloway \& Wansley, 1973a, 1973b; Stephan \& Kovacevic, 1978) outcomes.

In addition to learning associations between time of day and resources, there are pronounced daily changes in the ability to acquire new memories. For example, aplysia (Aplysia californica) show enhanced sensitization of gill withdrawal during subjective day (Fernandez, Lyons, Levenson, Khabour, \& Eskin, 2003). Cockroaches (Leucophaea maderae) learn to discriminate olfactory cues more effectively in subjective night (the phase of activity for nocturnal animals) than subjective day when held in constant conditions (Decker, McConnaughey, \& Page, 2007). Likewise, mice acquire maze navigation memory (Hoffmann \& Balschun, 1992) and contextual fear conditioning (CFC; Valentinuzzi et al., 2001) faster in the dark phase of the light-dark (LD) cycle. Interestingly, mice acquire tone-cued fear conditioning more rapidly when trained in the subjective day (Chaudhury \& Colwell, 2002). It is likely that these disparities in the timing of learning efficacy are stimulus specific, as similar discrepancies are observed across species. In rats, for example, the acquisition of maze navigation is better in the dark phase (Hauber \& Bareiss, 2001) or subjective night (Valentinuzzi, Menna-Barreto, \& Xavier, 2004), 
whereas active avoidance is learned better at the end of a 12-h light phase than at the beginning (Pagano \& Lovely, 1972). Hamsters demonstrate enhanced T-maze alternation and novel object discrimination performance during and just before the dark phase (Ruby et al., 2008, 2013). These time-of-day differences are not observed in the acquisition of more complex operant conditioning tasks (Ghiselli \& Patton, 1976; Stroebel, 1967; cf. Mistlberger et al., 1996). These latter findings suggest that the cognitive load of a task might overshadow changes from circadian timing, such that time-of-day modulation in acquisition may be more apparent on simpler tasks, but this hypothesis requires further investigation. Interestingly, tasks with a high cognitive load can themselves serve as zeitgebers (from German for "time giver," meaning they can shift circadian phase), apparently through cholinergic signaling (Gritton, Kantorowski, Sarter, \& Lee, 2012; Gritton, Stasiak, Sarter, \& Lee, 2013; Gritton, Sutton, Martinez, Sarter, \& Lee, 2009). These findings provide the basis for further dissecting the interaction of cognitive load and circadian modulation of learning and memory-dependent behavior.

Once acquired, the ability to recall and apply learned information peaks periodically following training. Early studies suggested that there was a 12-h period to recall efficacy: Rats were found to perform best on active avoidance, passive avoidance, and appetitive tests every $12 \mathrm{~h}$ after training (Holloway \& Wansley, 1973a, 1973b; Hunsicker \& Mellgren, 1977; Wansley \& Holloway, 1975, 1976; Figure 1A). Although the rate of acquisition was not found to change across the day, rats trained at the end of the light phase lacked 12-h peaks in recall performance, showing peaks only at 24-h intervals (Holloway \& Wansley, 1973b). Given that memories are most vulnerable to extinction during recall (Bridge \& Paller, 2012), one might expect to observe increased susceptibility to extinction with the same intervals posttraining, which is exactly what was observed (Holloway \& Sturgis, 1976). In contrast to this earlier work, more recent studies report a 24-h periodicity in recall efficacy following acquisition, without a 12-h intermediate peak (cf. Chaudhury \& Colwell, 2002; McDonald, Hong, Ray, \& Ralph, 2002; Figure 1B). For example, cockroaches exhibit peaks in operant conditioning every $24 \mathrm{~h}$ following training (Garren, Sexauer, \& Page, 2013). Hamsters show peak performance in appetitive (Ko et al., 2003; Ralph et al., 2002) and aversive (Cain, Chou, et al., 2004; Cain et al., 2008; Stephan \& Kovacevic, 1978) conditioning $24 \mathrm{~h}$ after training. Likewise, mice show peaks of recall in CFC $24 \mathrm{~h}$ following training (Loh et al., 2010). Whether rhythms in recall peak every 12 or $24 \mathrm{~h}$ following learning requires further investigation, as discrepancies between studies have not been explored systematically. It is possible that the disagreement with earlier works showing 12 -h periodic enhancement is due to rat-specific ultradian rhythms, but this possibility has not been examined.

As with daily rhythms in memory acquisition ability, recall and extinction also show a time-of-day dependence, independent of the time of training. Mice show more freezing when tested for contextual or tone-cued fear conditioning in the early subjective day, regardless of time of training (Chaudhury \& Colwell, 2002; EckelMahan et al., 2008). Similarly, rats display a peak in recall for passive avoidance in the light phase when housed in an LD cycle (Davies, Navaratnam, \& Redfern, 1974). In contrast, rates of extinction are greatest during the dark phase, consistent with the notion that acquisition (i.e., learning to disassociate a previously learned association) is acquired faster during the night, at least in nocturnal rodents. Under natural light, rats show faster extinction to conditioned taste aversion when extinction-trained at night (12:00 a.m. and 6:00 a.m.) than during the day (12:00 p.m. and 6:00 p.m.; note that the exact sunrise and sunset times for these data are not indicated in the manuscript; the designation of night and day comes from the author observing the natural LD cycle; Ternes, 1976). Similarly, mice exhibit a faster rate of extinction in CFC when conditioning and testing took place in subjective night (Valentinuzzi et al., 2001).

The ubiquity of circadian and daily changes in learning and memory does not permit an exhaustive review of the literature in the present overview (see Gerstner et al., 2009; Lyons, 2011; and Mulder, Gerkema, \& Van der Zee, 2013, for related reviews). However, from the examples given, it should be clear that there is pronounced circadian impact on the efficacy of acquisition, recall, and extinction, at least for some tasks. Given that the vast majority of studies on the circadian control of learning, memory, and recall have been performed in rodents, investigations into the similarities and differences across taxa represent an important area for further inquiry.

\section{The Master Clock and Circadian Changes in Learning and Memory}

In mammals, the circadian timing system is composed of a hierarchy of oscillators controlled by a central, master pacemaker in the suprachiasmatic nucleus ( $\mathrm{SCN}$ ) of the anterior hypothalamus. Lesions of the SCN abolish circadian rhythmicity (Moore \& Eichler, 1972; Stephan \& Zucker, 1972) and lead to a loss of synchrony among independent, subordinate oscillators throughout the CNS and periphery (Welsh, Yoo, Liu, Takahashi, \& Kay, 2004). Together, these findings suggest that the SCN communicates timing information to central and peripheral systems to maintain cohesion among independent cellular clocks required for system-specific rhythmicity (Figure 2).

At the cellular level, circadian rhythms are generated by $\sim 24-\mathrm{hr}$ autoregulatory transcriptional-translational feedback loops consisting of "clock" genes and their protein products (see Ko \& Takahashi, 2006, and Mohawk \& Takahashi, 2011, for review). In mammals, the feedback loop begins in the cell nucleus where CLOCK and BMAL1 proteins heterodimerize and drive the transcription of the Period (Per1, Per2, and Per3) and Cryptochrome (Cryl and Cry2) genes by binding to the E-box (CACGTG) domain on their gene promoters. Once translated, PER and CRY proteins build in the cytoplasm of the cell over the course of the day, and eventually form hetero- and homodimers that feed back to the cell nucleus to inhibit CLOCK:BMAL1-mediated transcription. The timing of nuclear entry is balanced by regulatory kinases that phosphorylate the PER and CRY proteins, leading to their degradation (Lowrey et al., 2000; G.-Q. Wang, Du, \& Tong, 2007). Two other promoter elements, DBP/E4BP4 binding elements ( $D$ boxes) and REV-ERB $\alpha /$ ROR binding elements (RREs; Ueda et al., 2005), also participate in cellular clock function. $\mathrm{REV}-\mathrm{ERB} \alpha$, an orphan nuclear receptor, negatively regulates the activity of the CLOCK:BMAL1.

Findings on the necessity of the SCN in mediating rhythms in the ability to learn or recall are equivocal. In rats, SCN lesions eliminate the enhancement in recall every $24 \mathrm{~h}$ following training 

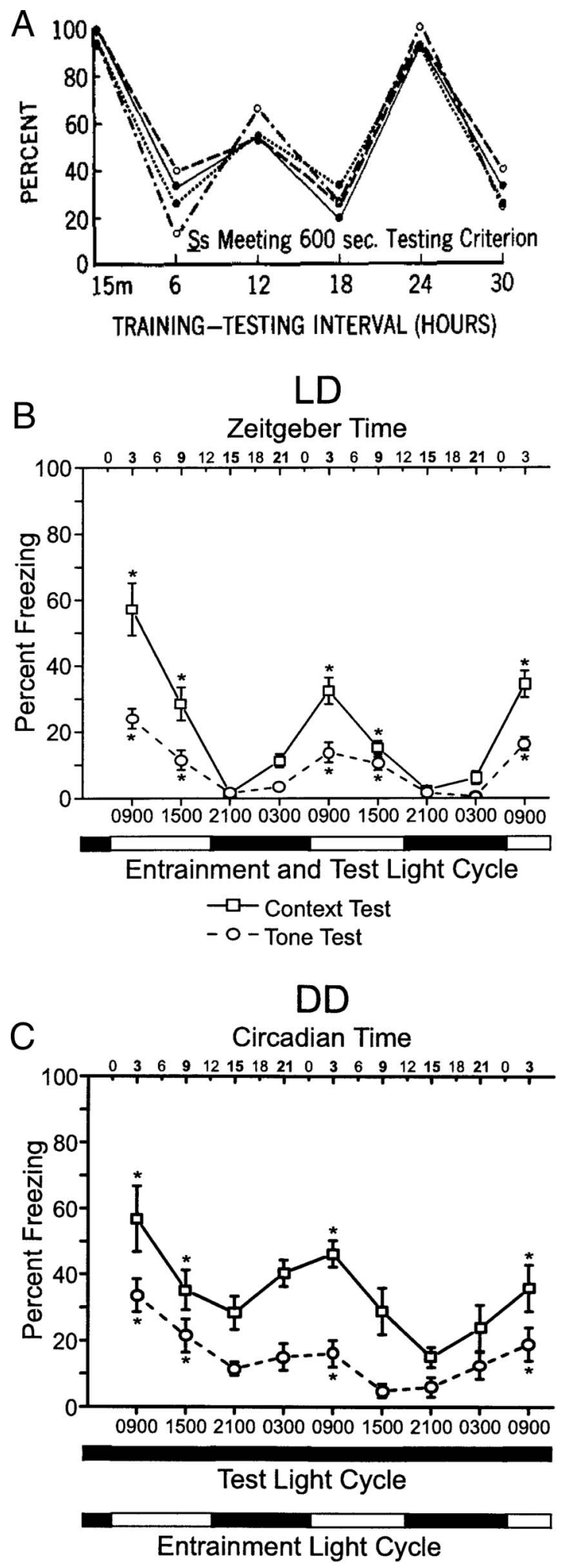

in a passive avoidance task (Stephan \& Kovacevic, 1978). In hamsters made arrhythmic without ablating the SCN, daily variance is lost in novel object recognition and T-maze alternation (Ruby et al., 2008, 2013). However, rats trained to perform a specific operant task depending on time of day are able to perform the correct lever operations at the correct time, even after SCN lesion (Mistlberger et al., 1996; Figure 3). Similarly, in some cases, SCN-ablated hamsters show conditioned place preference (CPP) only at the time during which training previously occurred (Ko et al., 2003), suggesting that the SCN was not needed for learning the "time stamp" of reward or, alternatively, for the 24-h periodicity of recall enhancement following training. Finally, whereas normal daily patterns of food and water foraging lose circadian rhythmicity following SCN ablation, animals under food or water restriction maintain the ability to learn time and place associations necessary to secure food or water when available (Marchant \& Mistlberger, 1997; Mistlberger, 1993).

The previous findings suggest that animals might be able to rely on periodic enhancement of recall when the SCN is absent, or that other subordinate circadian oscillators maintain the ability to track time for some tasks. For example, in hamsters trained on the CPP task discussed previously (Ko et al., 2003), olfactory cues and spatial cues were used together to establish the place memory. Olfactory information strongly modulates memory formation and recall, and the olfactory bulb $(\mathrm{OB})$ is itself a circadian oscillator (Granados-Fuentes, Tseng, \& Herzog, 2006). Therefore, the OB might serve as a source of circadian information for timed, scentspecific memories. Establishing time-coupled CPP in hamsters without scent cues would help to clarify the necessity of the SCN in circadian spatial memory formation and recall.

One other caveat that should be considered when evaluating these disparate findings is that periodic availability of food or water can entrain (synchronize) daily rhythms in physiology and behavior. Most species acquire food anticipatory behavior when food is restricted to a daily temporal window (reviewed in Aragona, Curtis, Davidson, Wang, \& Stephan, 2002; Carneiro \& Araujo, 2012; Mistlberger, 2011; Schibler, Ripperger, \& Brown,

Figure 1. Twelve- and 24-h periodic recall enhancement. Passive avoidance testing session, percent of sessions meeting the 600-s session criterion, showing 12-h periodic enhancement. From "Multiple Retention Deficits at Periodic Intervals After Active and Passive Avoidance Learning," by F. Holloway and R. Wansley, 1973, Behavioral biology, 9, p. 5. Copyright 1973 by Academic Press. Reprinted with permission. (A) Rhythms in recall in $\mathrm{C}-3 \mathrm{H}$ mice trained in the day (ZT/CT 3), showing 24-h periodic enhancement. In all experiments, animals were first tested for context 24-h posttraining then repeatedly tested every $6 \mathrm{~h}$, for 3 days. On Day 4, animals were tested for tone every $6 \mathrm{~h}$ for another 3 days. Testing was done at ZT/CT 3, 9, 15 and 21. (B) Mice were maintained on a light-dark (LD) cycle. (C) Mice were maintained in constant darkness (DD). Times of prior LD cycle are indicated. Each group contained eight animals. Within-population one-way repeated measures ANOVA at the first and second 24-h periods for both the context and tone showed significant differences in recall at different times of test, where the asterisk (*) denotes $p<0.05$. (B) and (C) from "Circadian Modulation of Learning and Memory in Fear-Conditioned Mice," by D. Chaudhury and C. Colwell, 1973, Behavioral Brain Research, 133, p. 100. Copyright 1973 by Elsevier Science B.V. Reprinted with permission. 


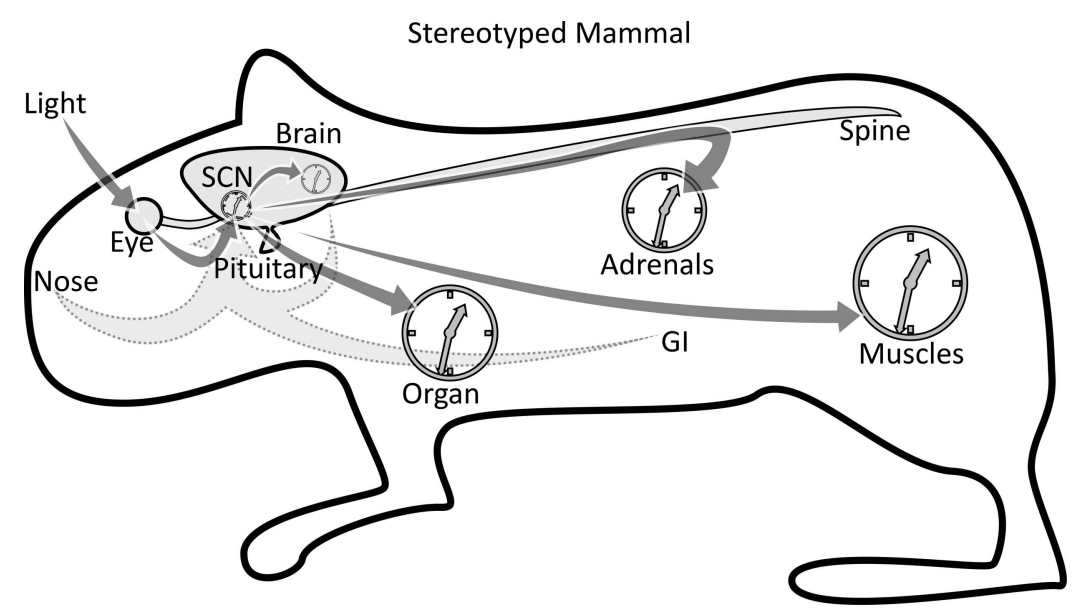

Figure 2. The suprachiasmatic nucleus ( $\mathrm{SCN}$ ) synchronizes extra-SCN oscillators throughout the body. A stereotyped mammal body showing that light input to the eyes is carried by the optic nerve to the master circadian pacemaker in the SCN. The SCN then sends phase information to synchronize the circadian oscillations of other neural nuclei and somatic systems. It accomplishes this task through many pathways, including spinal relay to the adrenals to regulate glucocorticoid rhythms, modulation of pituitary hormones to organ systems, and heretofore undefined signals to regulate muscle metabolism and activity output. The SCN also receives modulatory input from other oscillators, such as scent cues from olfaction, satiety cues from the gastrointestinal (GI) tract, and neural input from cognitive centers. A great deal remains to be examined in the mechanisms and effects of these interactions.

2003). Importantly, these food-seeking oscillations persist even in SCN-ablated animals (Stephan, Swann, \& Sisk, 1979), as does water seeking (Mistlberger, 1993). When investigating the circadian basis of appetitive learning in the absence of the SCN, food delivered as a reward might entrain the food entrainable oscillator (FEO) and confound interpretation if the task is performed at the same time each day. In agreement with this possibility, the three articles mentioned previously that established a strong link between the SCN and phasic recall enhancement (Ruby et al., 2008, 2013; Stephan \& Kovacevic, 1978) used purely spatial tasks, not likely vulnerable to the engagement of the olfactory oscillator or food-water entrainment. Careful conditioning paradigm selection will be needed to tease apart the potential roles of different circadian oscillators as cue-specific sources of temporal information for learning and memory.

\section{Circadian Disruption Impact Learning and Memory}

Circadian rhythms can be perturbed, without being eliminated, by a range of LD manipulations. These findings yield unique insights into the role of circadian information in memory formation in animals with an otherwise intact circadian system. In addition to altering the phase of the SCN, adjustments to the LD cycle also shift non-SCN oscillators (e.g., Smarr, Gile, \& de la Iglesia, 2013; Yamazaki et al., 2000). The SCN (at least the central core subregion) adjusts to pronounced phase shifts relatively rapidly (Best, Maywood, Smith, \& Hastings, 1999), compared with extra-SCN oscillators, which require considerably longer (Yamazaki et al., 2000). Phase shifts that precede training by 2 to 3 days result in recall deficits (Fekete, van Ree, Niesink, \& de Wied, 1985), a finding inconsistent with a model in which the SCN both provides a time stamp for new associations, and modulates recall efficacy. It is possible that extra-SCN oscillators (e.g., OB, FEO, etc.) contribute to memory acquisition and recall, as these oscillators may remain out of phase with the environment longer than the SCN. If extra-SCN oscillators provide time-stamped information for acquisition or recall of a memory, then a phase shift preceding a task should cause a phase mismatch between that memory's subjective time and the environment's or SCN's time. Because there is a periodic enhancement of recall following acquisition, a phase mismatch would result, following reentrainment between the time-stamped memory and environmental time, proportional to the magnitude of the phase shift. This being the case, an examination of recall efficacy at regular intervals following recovery from a phase shift should result in predictable mismatches between peak recall and environmental time. Alternatively, if phasic enhancements of recall were found to be lost in such experiments, this would imply that circadian disruption fundamentally impairs memory consolidation or recall. Such a systematic investigation has not yet been conducted, but ground work has been laid.

In mice trained on a CFC task within a day ( + or - ) of a 12-h phase shift, acquisition is normal, but major recall deficits are apparent at intervals of $24 \mathrm{~h}$ following the training. The magnitude of the deficit is proportional to both the size of the shift and to the distance in time from the shift. Either phase advances or phase delays cause these deficits (Loh et al., 2010). Rats also show deficits in recall when phase shifted, either advances (Davies et al., 1974; Fekete, Van Ree, \& De Wied, 1986; Tapp \& Holloway, 1981) or delays (Tapp \& Holloway, 1981), within a day of training on a passive avoidance task, and these deficits are proportional to the magnitude of shift (Fekete et al., 1986) and time since the shift (Fekete et al., 1985). Phase advances 5 days after training also impose recall deficits (Fekete et al., 1986). Rats trained in active avoidance tasks show enhanced extinction when 

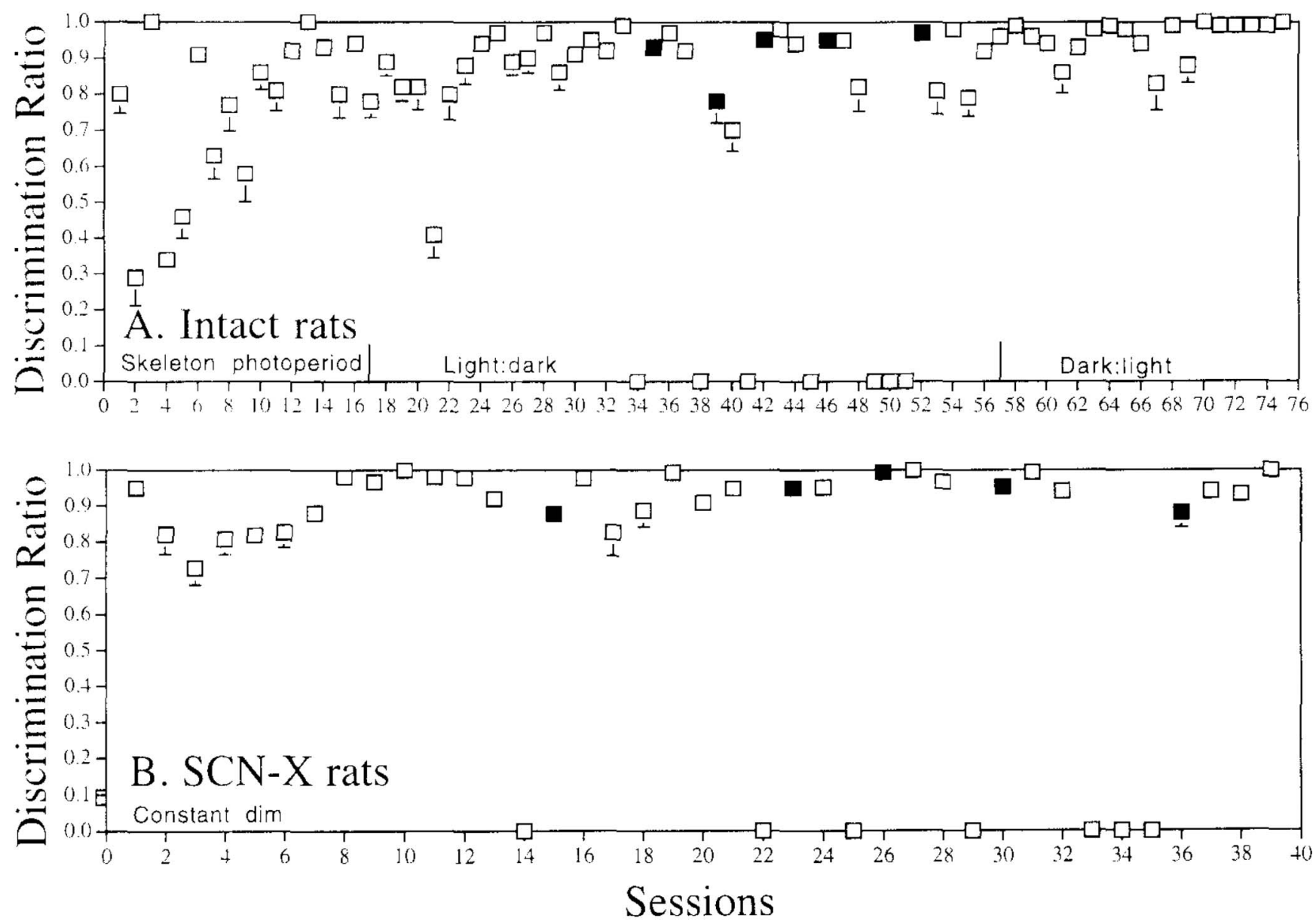

Figure 3. Conditioned place preference remains following suprachiasmatic nucleus (SCN) lesion. Group mean ( \pm SEM) discrimination ratios (number of correct lever presses divided by total lever presses, prior to the first reward of the session) for intact rats (top, $n=5$ ) and SCN-ablated rats (bottom, $n=5$ ) during Stage 4 of the experiment (two-arm free choice, $>1$ lever press required for first reward). Sessions that were omitted are indicated by the squares along the abscissa. The first test following an omission test is indicated by a solid square. From "Discrimination of Circadian Phase in Intact and Suprachiasmatic Nuclei-Ablated Rats," by R. Mistlberger, M. de Groot, J. Bossert, and E. Marchant, 1996, Brain Research, 739, p. 14. Copyright 1996 by Elsevier Science B.V. Reprinted with permission.

phase advances follow training (Fekete et al., 1986). In rats, at least following advances, time of day interacts with time since training, with normal acquisition occurring when trained in the early dark phase, and disrupted acquisition occurring when trained in the early light phase (Davies et al., 1974). Rats trained in a Morris water maze (MWM) following several days of phase advances show no deficit in acquisition (Craig \& McDonald, 2008; Devan et al., 2001), but day-to-day retention is negatively impacted (Devan et al., 2001). In Syrian hamsters, twice weekly phase advances (for 25 days) causes gross deficits on a CPP task; these deficits in the ability to learn the association persist even 4 weeks after the cessation of the phase advances (Gibson, Wang, Tjho, Khattar, \& Kriegsfeld, 2010). Finally, rats first subjected to several weeks of repeated phase advances show both acquisition and retention deficits when trained and tested in an MWM (Craig \& McDonald, 2008) and show deficits in CPP (McDonald et al., 2013), though, in the latter case, it is not clear if acquisition, recall, or both are impaired. Interestingly, phase shifts do not impair tone-cued conditioning (Craig \& McDonald, 2008) or social exploration (Fekete et al., 1985), and in aged hamsters, the magnitude of circadian rhythm degradation is not correlated with deficits in sexual behavior (Antoniadis, Ko, Ralph, \& McDonald, 2000), suggesting that only specific learning and memory tasks, but not all behaviors, are impacted by disruption of circadian rhythms. Taken together with the preceding behavioral examples, these phase-shifting experiments suggest that external time manipulations impose proportional deficits on recall, but only chronic phase shifting affects acquisition, particularly for spatial tasks, but not necessarily nonspatial tasks.

\section{The Hippocampus as an Integrator of Circadian Information With Learning and Memory}

The hippocampus (HC) is critical for forming an array of memories, including spatial associations (Anagnostaras, Gale, \& Fanselow, 2001; Corcoran \& Maren, 2001; Frohardt, Guarraci, \& 
Bouton, 2000), CFC (Anagnostaras et al., 2001), and, in some instances, tone-cued fear conditioning (Bast, Zhang, \& Feldon, 2003; Maren, Aharonov, \& Fanselow, 1997). As such, the HC is likely necessary for most of these tasks (excluding odor or gustatory cues). The HC may integrate circadian information through direct and indirect input from the SCN or other oscillator outputs, rhythms in hippocampal neurogenesis, hippocampal clock gene oscillations, and genetic modifications downstream of the molecular clockwork.

Direct and indirect circadian input to the HC. Few studies have investigated the specific means by which circadian disruption affects hippocampal functioning. One pair of studies suggest that the SCN may provide information to the HC through rhythms in GABAergic activity, as the administration of a GABA receptor A antagonist restores circadian rhythms in novel object recognition and T-maze alternation performance in arrhythmic, SCN-intact hamsters (Ruby et al., 2008, 2013). The specific mechanism(s), and neural pathway(s), by which arrhythmicity results in enhanced GABAergic communication to the $\mathrm{HC}$ requires further investigation.

An indirect pathway by which the HC might gain circadian information is adrenal glucocorticoids (CORT). Though CORT is not required for memory formation (Bialik, Pappas, \& Roberts, 1984), CORT modulates hippocampal neurogenesis (discussed in the section "Neurogenesis rhythms in the HC"), memory formation, and activation (reviewed in Maggio \& Segal, 2010; Schoenfeld \& Gould, 2012). Plasma CORT concentrations exhibit circadian rhythms, and SCN lesions eliminate (Abe, Kroning, Greer, \& Critchlow, 1979; Buijs, Kalsbeek, van der Woude, van Heerikhuize, \& Shinn, 1993; Moore \& Eichler, 1972), and circadian disruptions disturb (Lilley, Wotus, Taylor, Lee, \& de la Iglesia, 2012; Loh et al., 2010; Weinert, Eimert, Erkert, \& Schneyer, 1994; Wotus et al., 2013), normal CORT rhythms. Aging also disrupts and flattens circadian CORT rhythms (Cain, Karatsoreos, et al., 2004; Gartside, Leitch, McQuade, \& Swarbrick, 2003). The degree of flattening strongly correlates with deficits in CPP training (Cain, Karatsoreos, et al., 2004) and may cause structural changes in the HC (Gartside et al., 2003). These findings further suggest a role for CORT rhythms in memory acquisition and recall. Rhythms in CORT appear to be indirectly driven by arginine-vasopressin (AVP) from the SCN, acting to inhibit ACTH (Gomez et al., 1997; Kalsbeek, Buijs, van Heerikhuize, Arts, \& van der Woude, 1992; Kalsbeek, van Heerikhuize, Wortel, \& Buijs, 1996), a neuropeptide that drives CORT release from the adrenals. Administration of ACTH (Pagano \& Lovely, 1972) or its analog ORG-2766 (Fekete et al., 1986), or the AVP analog desglycinamide9-(Arg8)vasopressin (Fekete et al., 1986), mitigate the time-of-day effect on learning (as do lesions of the adrenal gland and its innervation; Bialik et al., 1984), and the negative impact of phase shifts on memory. Adrenalectomy impairs CFC recall, and CORT replacement rescues this effect (Pugh, Tremblay, Fleshner, \& Rudy, 1997). Augmenting conditioning with anxiolytic treatments eliminates time-of-day variance in long-term recall (Coll-Andreu, Martí-Nicolovius, \& Morgado-Bernal, 1991), whereas CORT concentrations in response to CFC training predicts the strength of CFC retention (Cordero, Merino, \& Sandi, 1998). Finally, circadian changes in CORT concentrations may interact with stressinduced increases in CORT to mediate changes in learning strength in response to stress at different times of day (Kelliher et al., 2000; Rudy \& Pugh, 1998).

Clock gene rhythms in HC. Further evidence for the role of the $\mathrm{HC}$ as a center for circadian influence on learning and memory comes from the observation that hippocampal cells express clock genes and keep circadian time. As mentioned previously, clock genes are expressed ubiquitously in the CNS and periphery, allowing for tissue-specific rhythms in activity and the maintenance of optimal health and functioning. Clock genes are expressed rhythmically in the HC, including the dentate gyrus (Jilg et al., 2010). Although a few studies have failed to observe hippocampal rhythms in Per2 expression in mice (Albrecht, Sun, Eichele, \& Lee, 1997; Borgs, Beukelaers, Vandenbosch, Nguyen, et al., 2009), perhaps due to its relatively low amplitude (Jilg et al., 2010), rhythms in Per1, Cry1, Cry2, Clock, and Bmall mRNA, and protein in the HC, have been consistently observed in rats, mice, and hamsters (Amir, Harbour, \& Robinson, 2006; Chaudhury, Loh, Dragich, Hagopian, \& Colwell, 2008; Duncan, Prochot, Cook, Tyler Smith, \& Franklin, 2013; Gilhooley, Pinnock, \& Herbert, 2011; Ikeno, Weil, \& Nelson, 2013; Jilg et al., 2010; Lamont, Robinson, Stewart, \& Amir, 2005; Segall, Milet, Tronche, \& Amir, 2009; Segall, Perrin, Walker, Stewart, \& Amir, 2006; Valnegri et al., 2011; Wakamatsu et al., 2001; L. M. Wang et al., 2009; Wyse \& Coogan, 2010). Furthermore, hippocampal slices continue to oscillate in culture (L. M. Wang et al., 2009), suggesting the existence of independent oscillations presumably synchronized by the SCN in vivo. The dentate gyrus rhythm of Per2 in rats persists even after electrolytic lesion of the SCN (Lamont et al., 2005) or after disruption of circadian CORT fluctuations (Segall et al., 2006, 2009), further suggesting the HC functions as an extra-SCN oscillator, potentially mediating maintenance of rhythms in learning and memory after SCN ablation.

Rhythms in cellular cascades in the HC. In addition to the rhythmic expression of clock genes, intracellular cascades important for transducing cellular responses oscillate with a circadian cycle (Dolci et al., 2003; Eckel-Mahan et al., 2008; Phan et al., 2011). For example, cyclic adenosine monophosphate (cAMP)/ cAMP response element binding protein (CREB) and mitogen activated protein kinase (MAPK) are rhythmic in the $\mathrm{HC}$, and these rhythms are disrupted by exposure to constant light or SCN ablation (Eckel-Mahan et al., 2008; Phan et al., 2011). cAMP and MAPK pathways are necessary intracellular signaling cascades in the molecular clockwork (Antoun, Bouchard-Cannon, Cannon, \& Cheng, 2012; Butcher, Lee, Cheng, \& Obrietan, 2005; Dziema et al., 2003; Obrietan, Impey, \& Storm, 1998; Tischkau, Gallman, Buchanan, \& Gillette, 2000). MAPK phosphorylates BMAL1, a central component of the circadian clock, inhibiting BMAL1: CLOCK heterodimer-dependent transcription of the Per and Cry genes (Sanada, Okano, \& Fukada, 2002). The Perl and Per2 promoters contain cAMP response element (CRE) sites that bind CREB to enhance their protein production (Travnickova-Bendova, Cermakian, Reppert, \& Sassone-Corsi, 2002).

Given that cAMP/CREB and MAPK have been implicated in the formation and persistence of long-term memory (Athos, Impey, Pineda, Chen, \& Storm, 2002; Atkins et al., 2010; Kelleher, Govindarajan, Jung, Kang, \& Tonegawa, 2004; Kelly, Laroche, \& Davis, 2003; Lonze \& Ginty, 2002; Scott, Bourtchuladze, Gossweiler, Dubnau, \& Tully, 2002; Silva, Kogan, Frankland, \& Kida, 1998; H. Wang, Ferguson, Pineda, Cundiff, \& Storm, 2004), it is 
likely that long-term memory may be modulated by the regulation of the circadian molecular clock by shared intracellular signaling pathways. In agreement with this possibility, the disruption of MAPK oscillations following training interferes with persistence of long-term memory (Eckel-Mahan et al., 2008). Likewise, Perl and Per2 knockouts exhibit deficits in hippocampal-dependent learning tasks associated with abnormal long term potentiation (LTP; discussed below in the section "Circadian Influence on Long-Term Potentiation in the HC") and reduced levels of phosphorylated CREB in Per2 knockouts (L. M. Wang et al., 2009). These results have led to the suggestion that long-term memory may depend on the circadian-driven reactivation of the cAMP/ CREB and MAPK pathways required to consolidate memories (Eckel-Mahan, 2012; Eckel-Mahan et al., 2008; Gerstner et al., 2009).

Neurogenesis rhythms in the HC. A local mechanism by which circadian information may influence $\mathrm{HC}$ functioning is through changes in adult hippocampal neurogenesis. New neurons are born from neural progenitor cells in the subgranular zone of the dentate gyrus. These adult-born neurons are eventually integrated into the granule layer, where they appear to contribute to spatial pattern recognition and hippocampal-dependent memory (reviewed in Deng, Aimone, \& Gage, 2010). Numerous lines of evidence support an association between adult neurogenesis and learning and memory. For example, neurogenesis is increased after hippocampal-dependent learning, but not after hippocampalindependent learning (Ambrogini et al., 2000; Epp, Spritzer, \& Galea, 2007; E. Gould, Beylin, Tanapat, Reeves, \& Shors, 1999; Leuner et al., 2004; van der Borght, Meerlo, Luiten, Eggen, \& Van der Zee, 2005). Furthermore, disrupting neurogenesis via a number of techniques similarly disrupts performance on hippocampaldependent tasks (Clelland et al., 2009; Dupret et al., 2007; FarioliVecchioli et al., 2008; Shors et al., 2001). However, a growing body of evidence suggests that adult hippocampal neurogenesis may only be necessary for relatively complex spatial learning (Dupret et al., 2008; Saxe et al., 2006; Shors, Townsend, Zhao, Kozorovitskiy, \& Gould, 2002).

The dentate gyrus exhibits circadian rhythms in neurogenic proliferation under certain conditions (see Mueller, Mear, \& Mistlberger, 2011, for review). Briefly, rhythms in proliferation across the day have been found in rats (Gilhooley et al., 2011; GuzmanMarin, Suntsova, Bashir, Szymusiak, \& McGinty, 2007), mice (Tamai, Sanada, \& Fukada, 2008), and hamsters (Smith, Hechtman, \& Swann, 2010). Some studies in rats (Ambrogini et al., 2002; Mueller et al., 2011) and mice (Holmes, Galea, Mistlberger, \& Kempermann, 2004; van der Borght et al., 2006) have not observed rhythms in proliferation, whereas one study in mice observed rhythmic proliferation in the hilus but not in the subgranular zone, indicating there may be a time-of-day effect in gliogenesis but not neurogenesis (Kochman, Weber, Fornal, \& Jacobs, 2006). These differences are likely due to differences in experimental methodology, such as proliferative markers used or injection or survival protocols (see Mueller et al., 2011). Also of note, one study that reported no proliferative rhythms in nonmanipulated animals did find an interaction between circadian time and exercise-induced increases in cell proliferation. Wheel running increased mouse hippocampal cell proliferation only when given during the active phase (Holmes et al., 2004). Thus, although the existence of adult neurogenesis was formerly controversial, it seems clear that, at least under certain conditions, there is circadian regulation in the proliferative component of hippocampal neurogenesis, with several thousand new cells generated daily in the rodent HC (Cameron \& McKay, 2001; Rao \& Shetty, 2004).

Perhaps not surprisingly, hippocampal neurogenesis is likely regulated by hippocampal clock genes. Many cell cycle-related genes show circadian patterns of expression, and at least some are under transcriptional regulation by the CLOCK-BMAL1 complex (Matsuo et al., 2003; reviewed in Borgs, Beukelaers, Vandenbosch, Belachew, et al., 2009). Manipulations of Perl, both Cry genes, or Clock in mice induce alterations in cell growth and cell cycle progression (Gery et al., 2006; Matsuo et al., 2003; Miller et al., 2007). The cell cycle in neural progenitor cells is estimated to be $24.7 \mathrm{~h}$ (Cameron \& McKay, 2001; though this likely changes with the individuals' and species' free funning period), further suggesting an important role for circadian timing in progenitor cell maturation and differentiation. One study in mice found that neural progenitor cell expression of Per2 is maintained throughout differentiation into mature neurons (Borgs, Beukelaers, Vandenbosch, Nguyen, et al., 2009). However, Per2 might have clockunrelated functions in these cells, as this study found Per2 to be expressed constitutively in the dentate gyrus.

Outside of the HC, Clock and Bmall are also expressed in neural progenitor cells of the subventricular zone (SVZ) of mice, an area which gives rise to new neurons destined for the olfactory bulbs (Kimiwada et al., 2009). These clock genes change expression patterns as these adult-born cells differentiate into mature neurons, suggesting a role in neuronal differentiation. Furthermore, when Clock or Bmall are silenced by RNA interference, SVZ neurogenesis is decreased (Kimiwada et al., 2009), further supporting their role as neurogenic regulators. It is currently unknown whether these genes serve the same function in hippocampal neurogenesis.

Rhythmic signals affecting neurogenesis in the HC. Because circadian rhythms are ubiquitous, pinpointing the specific neurochemical systems and cellular pathways by which the circadian system influences hippocampal functioning has been challenging. Nonetheless, a number of promising leads present themselves in the literature. CORT was described earlier and will not be revisited, except to point out its potential in this category. The brainderived neurotrophic factor (BDNF) is a positive regulator of neurogenesis (Rossi et al., 2006; Sairanen, Lucas, Ernfors, Castrén, \& Castrén, 2005; Taliaz, Stall, Dar, \& Zangen, 2010) that acts through its receptor TrkB, leading to downstream activation of MAPK. BDNF and TrkB are expressed rhythmically in the HC (Bova, Micheli, Qualadrucci, \& Zucconi, 1998; Dolci et al., 2003; Ikeno et al., 2013), suggesting circadian regulation of BDNF activity. Indeed, sleep and circadian disruption impacts BDNF levels in the $\mathrm{HC}$, with the direction of change varying with disruption type and length (Fujihara, Sei, Morita, Ueta, \& Morita, 2003; Guzman-Marin et al., 2006; Sei, Saitoh, Yamamoto, Morita, \& Morita, 2000; Sei et al., 2003). Melatonin and its precursor, $\mathrm{N}$-acetylserotonin (NAS), also show circadian rhythmicity, rising during nighttime and falling during daytime (Ganguly, Coon, \& Klein, 2002). Melatonin promotes immature neuron survival and neurogenesis (Ramírez-Rodríguez, Klempin, Babu, Benítez-King, \& Kempermann, 2009; Ramirez-Rodriguez, Ortíz-López, DomínguezAlonso, Benítez-King, \& Kempermann, 2011; Rennie, De Butte, \& Pappas, 2009), possibly through antioxidant activity (Manda \& Reiter, 2010). On the other hand, NAS promotes proliferation by acting 
through the BDNF receptor TrkB in the HC (reviewed in Sompol et al., 2011; Tosini, Ye, \& Iuvone, 2012), which it activates in a circadian manner (Jang et al., 2010).

\section{Circadian Disruption Impairs Hippocampal Neurogenesis}

Consistent with a view in which clock gene signaling and neurogenesis in the $\mathrm{HC}$ are critical to some forms of learning and memory, disruptions in clock gene function or circadian rhythmicity are associated with impaired hippocampal neurogenesis and learning and memory. Per2 mutant mice display increased proliferation and neuronal death, though this results in similar net numbers of adult-born mature neurons as wildtype mice (Borgs, Beukelaers, Vandenbosch, Nguyen, et al., 2009). The timing of survival, differentiation, and integration of new neurons to the granule layer is critical for functional hippocampal-dependent memory (Dupret et al., 2007; FarioliVecchioli et al., 2008). Therefore, although total neurogenesis in Per2 mutants appears unaffected (Borgs, Beukelaers, Vandenbosch, Nguyen, et al., 2009), the neurogenic contribution to learning and memory could still be disrupted by the clock gene mutation in these animals, and this possibility warrants investigation. It is also important to consider that neural progenitor cells and immature neurons are exposed to daily rhythms in hormones, including CORT. Clamping glucocorticoids to a stable high level eliminates Perl-luciferase rhythms in the rat $\mathrm{HC}$ and reduces proliferation (Gilhooley et al., 2011), suggesting a potential mechanism by which chronic stress negatively impacts learning and memory.

Repeated phase shifts (i.e., jet lag) disrupt the circadian system and impair neurogenesis. In hamsters, for example, repeated 6-h phase advances grossly reduce hippocampal neurogenesis, as well as impair performance in a hippocampaldependent memory task (Gibson et al., 2010; Figure 4). Jet-laginduced reduction in cell proliferation is glucocorticoid dependent, and is abolished by adrenalectomy with CORT replacement. This fits with findings that stress and increased glucocorticoids impair neurogenesis (Mirescu \& Gould, 2006). In contrast, jet-lag-induced reductions in total neurogenesis (as measured by labeling dividing cells repeatedly throughout 25 days of jet lag) are glucocorticoid independent and not affected by adrenalectomy, indicating that phase shifts can impair neurogenesis independent of the canonical stress response (Gibson et al., 2010). Furthermore, the manipulation used in this experiment resulted in animals that maintained circadian activity rhythms out of alignment with the external LD cycle. Thus, it is not necessarily circadian disruption that reduces neurogenesis, but rather a mismatch between internal physiology and external time (or the SCN, which more closely tracks external time). Similar results are observed in rats exposed weekly to 6-h phase advances or delays for 4 or 8 weeks (Kott, Leach, \& Yan, 2012). In this study, the number of immature neurons decreased with increasing duration of jet lag, and was reduced by phase advances more than phase delays. These results are consistent with previous findings indicating that phase advances require more time for reentrainment of the molecular clock than phase delays (Reddy, Field, Maywood, \& Hastings, 2002).
Housing animals in constant bright light (LL) alters circadian rhythms in hormones and behavior in rats and mice, and is a useful tool to examine the impact of disruptions in circadian timing. Reports of the effects of housing in LL on neurogenesis have yielded equivocal results. Mice housed in LL exhibit a reduction in neurogenesis, along with impaired performance in a hippocampal-dependent task (Fujioka et al., 2011). However, rhythmicity was not characterized in these animals, precluding a determination of the extent of circadian disruption (Fujioka et al., 2011; Mueller et al., 2011). In rats housed under LL for 4 days, 3 weeks, or 10 weeks, neither 4 days nor 10 weeks of continuous light affected cell proliferation, whereas 3 weeks of light did not affect cell survival (Mueller et al., 2011). Although these results are in apparent disagreement with studies of jet lag in hamsters and rats, it is noteworthy that jet lag results in mismatch between internal and external cues (Gibson et al., 2010), whereas in constant light there are no periodic environmental cues to impose acute mismatch (Mueller et al., 2011). It is possible that this periodic mismatched input is more detrimental to neurogenesis than the stable disturbance to circadian rhythmicity resulting from LL exposure. Indeed, resonance between the circadian clock and environmental light cycle has been associated with increased survival and fitness in many organisms (Ouyang, Andersson, Kondo, Golden, \& Johnson, 1998; Pittendrigh \& Minis, 1972; Wyse, Coogan, Selman, Hazlerigg, \& Speakman, 2010). Resonance may also lend benefits to hippocampal neurogenesis.

Sleep disruption impairs neurogenesis, but it is difficult to distinguish effects due to sleep disruption versus circadian disruption, as the two systems are intertwined. Studies of sleep disruption on neurogenesis have not traditionally controlled for differential effects on the circadian versus sleep systems. Numerous studies on sleep deprivation or fragmentation have shown that long-term sleep disruption impairs neurogenesis (Guzman-Marin, Bashir, Suntsova, Szymusiak, \& McGinty, 2007; Guzmán-Marín et al., 2003; Guzman-Marin et al., 2005, 2008; Mirescu, Peters, Noiman, \& Gould, 2006; Mueller et al., 2008, 2011; Sportiche et al., 2010), whereas short-term sleep disruption may temporarily increase proliferation (see Junek, Rusak, \& Semba, 2010, and references therein). Sleep deprivation has also been shown to block learning-induced increases in neurogenesis (Hairston et al., 2005). As this review is focused on the circadian system, these studies will not be addressed in depth here.

There is a growing body of evidence suggesting that circadian regulation of adult hippocampal neurogenesis may contribute to rhythms in learning and memory. Clock genes are expressed rhythmically in the dentate gyrus (Jilg et al., 2010), including hippocampal neural progenitor cells (Borgs, Beukelaers, Vandenbosch, Nguyen, et al., 2009), in which they may act to generate proliferative rhythms (Gilhooley et al., 2011; Goergen, Bagay, Rehm, Benton, \& Beltz, 2002; GuzmanMarin, Suntsova, et al., 2007; Smith et al., 2010; Tamai et al., 2008) and regulate differentiation into mature neurons (Kimiwada et al., 2009). This hypothesis is supported by the findings that disruption of the circadian system negatively impacts neurogenesis (Fujioka et al., 2011; Gibson et al., 2010; Kott et al., 2012), although mismatch between internal and external time, 
A

$\frac{\infty}{0}$

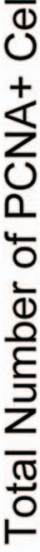

3000

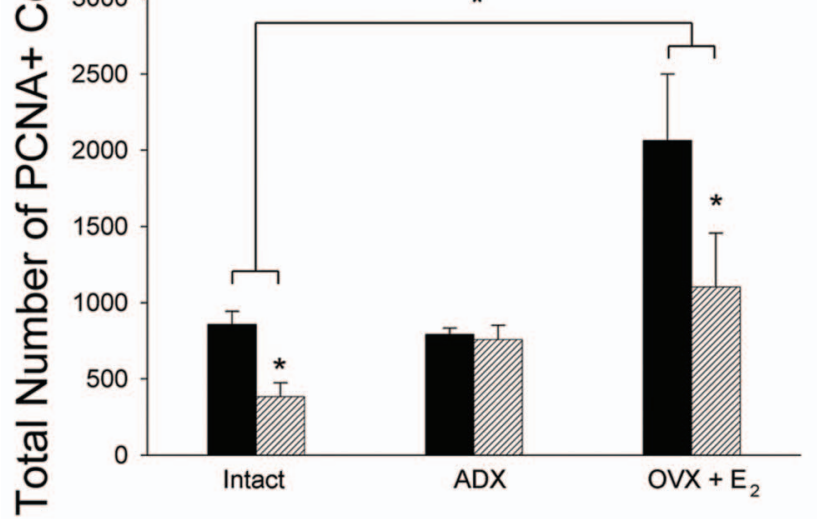

B

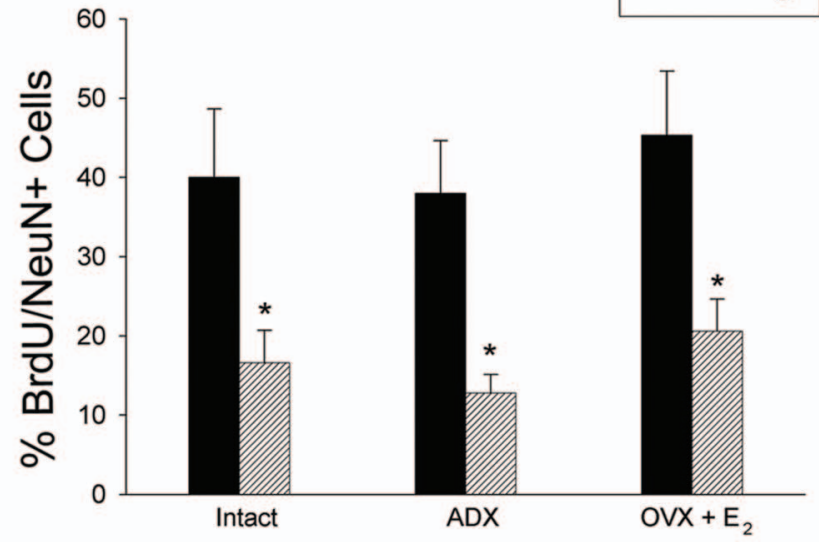

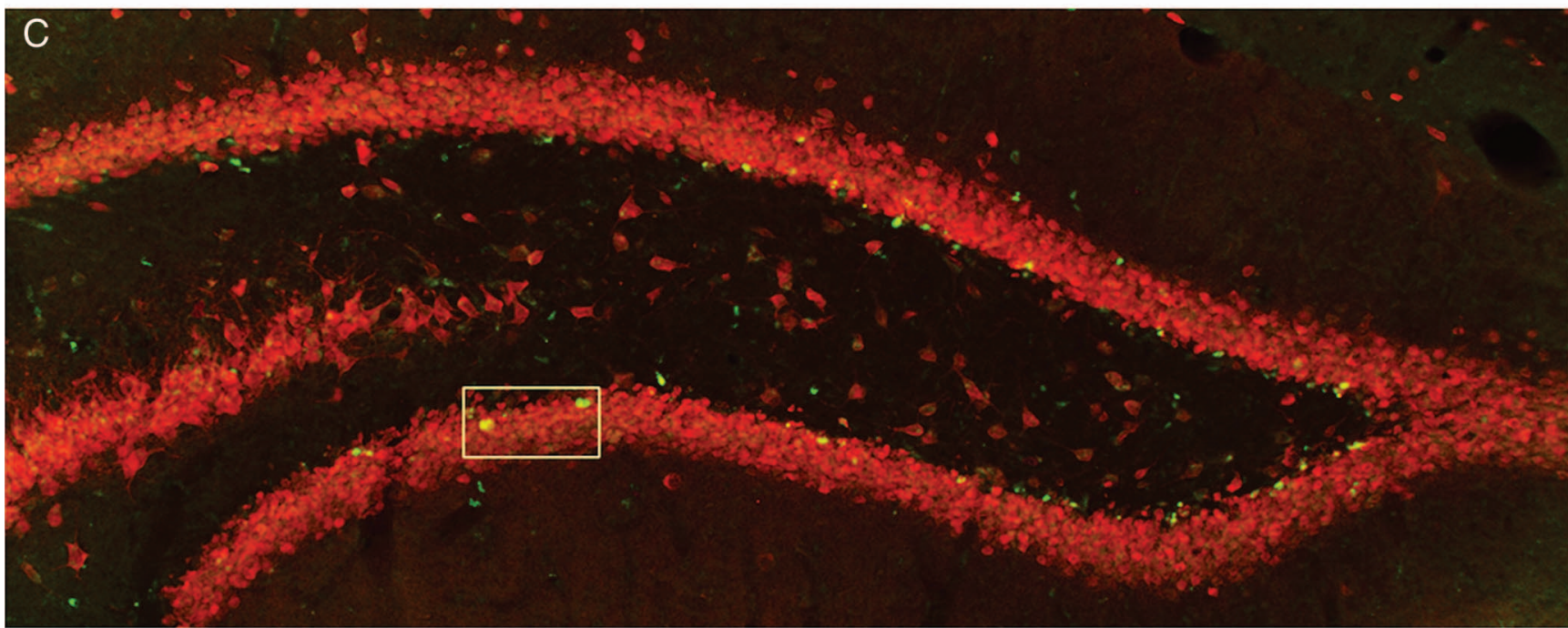
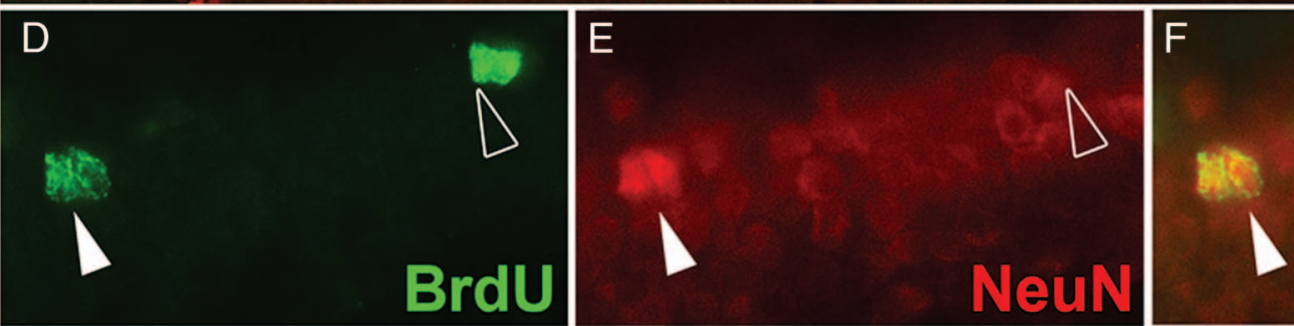

Figure 4. Jet lag impacts hippocampal neurogenesis. (A) The number of PCNA-labeled cells in the granule cell layer was affected by the hormonal condition of the animal, $F(2,20)=4.014, p=.03$, with ovariectomy and estradiol replacement significantly increasing the number of labeled cells compared with intact hamsters $(p=.04)$. Jet lag resulted in a significant decrease in the number of proliferating cell nuclear antigen (PCNA)-labeled cells in both intact and OVX $+\mathrm{E} 2$ hamsters ( $p=.007$ and $p=.05$, respectively, by planned comparisons), whereas the number of PCNA-labeled cells in adrenalectomized animals was not affected by chronic temporal disruption $(p=.80)$. (B) Neurogenesis was decreased by jet lag, $F(1,21)=20.147, p<.001$, but there was no significant effect of hormone condition, $F(1,21)=0.228, p=.80$, and no interaction, $F(2,21)=0.231, p=.80$. Chronic jet lag resulted in a decrease in neurogenesis by $>50 \%$ in intact, $\mathrm{ADX}$, and OVX + E2 hamsters $(p=.01, p=.007$, and $p=.05$, respectively; ${ }^{*} p<.05 ; n=4$ to 5 animals per group). (C-F) Sections were processed for double-label BrdU (green) and NeuN (red), a marker for mature neurons, and quantified at 400×. (C) Photomicrograph of the dorsal and ventral blades of the dentate gyrus. Cells were considered double-labeled when BrdU (D) and NeuN (E) colocalized in the same focal plane (F; yellow). From "Experimental 'Jet Lag' Inhibits Adult Neurogenesis and Produces Long-Term Cognitive Deficits in Female Hamsters," by E. Gibson, C. Wang, S. Tjho, N. Khattar, and L. Kriegsfeld, 2010, PLoS One, 5, p. 5. Open-source copyright 2010 by PLoS One. Reprinted with permission. 
rather than arrhythmicity, may be of greatest concern (Mueller et al., 2011).

\section{Circadian Influence on Long-Term Potentiation in the $\mathrm{HC}$}

LTP, the transient increase in synaptic strength between neuronal connections, is widely considered to be the canonical model of information storage among neural circuits, and thus is postulated as the underlying physiological mechanism of learning and memory (for review, see Malenka, 2003; Martin, Grimwood, \& Morris, 2000; Martinez \& Derrick, 1996; Sweatt, 2001). Electrophysiological recordings in the $\mathrm{HC}$ show circadian variation in the induction of LTP in vivo (Barnes, McNaughton, Goddard, Douglas, \& Adamec, 1977; Cauller, Boulos, \& Goddard, 1985; Dana \& Martinez, 1984; Harris \& Teyler, 1983; West \& Deadwyler, 1980) and in vitro (Chaudhury, Wang, \& Colwell, 2005; Kole, Koolhaas, Luiten, \& Fuchs, 2001; Nishikawa, Shibata, \& Watanabe, 1995; Raghavan, Horowitz, \& Fuller, 1999). In rats, for example, excitatory postsynaptic potentials (EPSPs) are 30\% larger when LTP is induced during the night compared with the day (Barnes et al., 1977). This rhythm persists in enucleated rats and exhibits a "free running" rhythm, consistent with the notion that these rhythms are endogenously generated. Similarly, diurnal squirrel monkeys exhibit larger EPSP amplitude during the day, antiphase to that of nocturnal rats (Barnes et al., 1977). These results suggest the circadian system acts on the $\mathrm{HC}$ to maximize learning potential at times relevant to the life history of the animal.

In mouse hippocampal slice recordings of CA1, LTP induced during the dark phase results in an increase in amplitude of the population spikes with a slower decay of field EPSPs, relative to daytime induction (Chaudhury et al., 2005). When housed in constant darkness, this enhancement of LTP persists in subjective night, indicating endogenous control rather than a response to external temporal cues. Interestingly, when hippocampal slices are harvested during the light or dark phase, and then recorded in the opposite phase, the induction of LTP follows that of the light cycle rather than that of the circadian phase at the time the tissue was harvested (Chaudhury et al., 2005; Raghavan et al., 1999). This result is consistent with the idea that the $\mathrm{HC}$ oscillates in a circadian manner, independent of the $\mathrm{SCN}$, providing a local mechanism to drive daily changes in LTP potential. Under natural circumstances, this independent hippocampal oscillation is likely synchronized to local time by the SCN and requires master clock input to maintain coherence among populations of hippocampal cells. Although these findings point to a role for the circadian timing system in hippocampal LTP, significant variability exists among studies, likely due to differences in experimental and recording strategies (Cauller et al., 1985; Harris \& Teyler, 1983; Raghavan et al., 1999; West \& Deadwyler, 1980).

Although the evidence already presented suggests the potential for local, circadian control at the level of the HC, the fact that LTP expression can be altered by an array neuromodulators and hormones (Lisman, 2003; Silva, 2003) under potential circadian control implies that neural and hormonal inputs impinging on hippocampal oscillators likely contribute to daily regulation of LTP. CORT can alter the expression of hippocampal LTP (Diamond, Bennett, Fleshner, \& Rose, 1992; Filipini, Gijsbers, Birmingham, \& Dubrovsky, 1991; Joëls \& Krugers, 2007). Likewise, adrena-

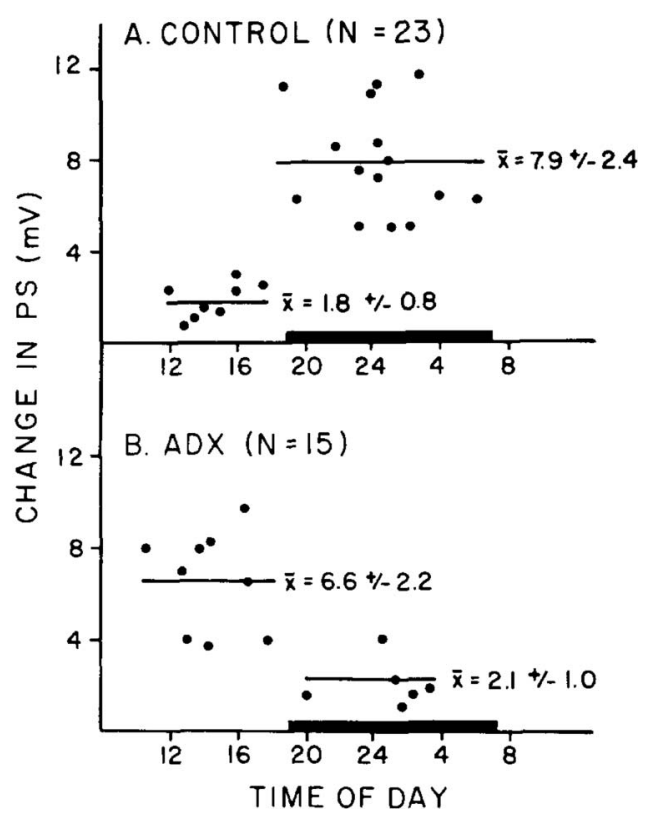

Figure 5. Long-term potentiation (LTP) daily oscillations are shaped by adrenals. The circadian rhythm of LTP in the dentate gyms. (A) Intact control animals. (B) ADX animals (adrenalectomy was performed at least $72 \mathrm{~h}$ prior to testing and animals were maintained on normal saline in their water bottles). Each point represents the $\mathrm{mV}$ increase in population spike amplitude (PS) for one animal measured 20 rain following tetanization. The time indicates when the conditioning train was delivered to the perforant path. A thin horizontal bar represents the mean $\mathrm{mV}$ increase for groups of animals in which LTP was studied during either the light or dark period. To the right of each thin bar is the mean plus or minus S.D. The dark horizontal bars represent the colony dark periods (19.00-07.00). From "Effect of Adrenalectomy on the Circadian Rhythm of LTP," by R. Dana and J. Martinez, Jr., 1984, Brain research, 308, p. 393. Copyright 1984 by Elsevier Science Publishers B.V. Reprinted with permission.

lectomized rats exhibit a shift from a nocturnal to a diurnal enhancement of LTP, with the same amplitude of circadian variation, suggesting an important role for CORT likely in hippocampal LTP rhythmicity (Dana \& Martinez, 1984; Figure 5). Melatonin has also been shown to be a modulator of LTP induction (Collins \& Davies, 1997; El-Sherif, Tesoriero, Hogan, \& Wieraszko, 2003). However, hippocampal slice recordings from C57 mice, which lack melatonin, maintain dark-phase enhancement of LTP (Chaudhury et al., 2005). The amplitude of the daily rhythm is smaller in $\mathrm{C} 57$ melatonin-lacking mice relative to $\mathrm{CH} 3$ mice, which do rhythmically secrete melatonin (Chaudhury et al., 2005), suggesting that melatonin may be working in parallel with the local hippocampal oscillations to adjust the gain of the LTP response under normal circumstances. These studies suggest that although circadian control of hormone release is a way of adjusting the rhythmic expression of LTP, the relationship between the circadian system and hippocampal synaptic connectivity is complex and needs further study.

\section{Circadian Rhythms and Synaptic Morphology}

Learning, in the $\mathrm{HC}$ and elsewhere, is associated not just with making new neurons or affecting the efficiency of existing syn- 
apses, but more classically with modifying existing neural networks through changes in synaptic morphology (reviewed in Caroni, Donato, \& Muller, 2012; Tronel et al., 2010). These changes impact spine density and dendritic complexity, both of which provide additional targets mediating circadian influences on learning and memory. These structural changes are associated with the formation of new synapses or the fine tuning of synaptic strength (Caroni et al., 2012). Rats exhibit increases in dendritic length, complexity, and spine density in the Layer III infralimbic cortex during the dark phase of the LD cycle, with greater changes seen in basilar dendrites relative to apical dendrites (Perez-Cruz, Simon, Flügge, Fuchs, \& Czéh, 2009). Diurnal rhythms in synaptic morphology have also been observed in the HC in Siberian hamsters (Ikeno et al., 2013). In this species, rhythms in basilar dendritic complexity are observed in the CA1 subregion of the HC, but not the dentate gyrus; however, spine density fluctuates in both regions. Interestingly, these rhythms are photoperiod dependent; for example, only animals housed in long-day, summer-like photoperiods exhibited daily rhythms in the number of primary dendrites, whereas only animals housed in short-day, winter-like day lengths displayed rhythmic changes in dendritic length (Ikeno et al., 2013), indicating a potential interaction with circannual rhythms of sex hormones.

Circadian influences on synaptic morphology may be mediated through rhythmic changes in upstream neurochemicals, including glucocorticoids, melatonin, or BDNF. Glucocorticoids grossly impact synaptic morphology in the HC (Watanabe, Gould, \& McEwen, 1992; Woolley, Gould, \& McEwen, 1990) and were recently shown to regulate spine formation in the mouse motor cortex after motor learning (Liston et al., 2013). Peaks in daily glucocorticoid levels promote postsynaptic spine formation via a rapid, nontranscriptional mechanism, whereas troughs are important for stabilizing newly formed spines. However, this effect has not been clearly demonstrated in the $\mathrm{HC}$, and so whether this effect is present in the $\mathrm{HC}$ and hippocampal-dependent learning represents an important opportunity for further exploration. Separately, melatonin, which is released during the dark phase, positively regulates dendritic complexity in the HC (González-Burgos, Letechipía-Vallejo, López-Loeza, Moralí, \& Cervantes, 2007; Ramirez-Rodriguez et al., 2011). Finally, BDNF is a well-established regulator of synaptic plasticity and remodeling (reviewed in Koleske, 2013) and exhibits daily fluctuations in the HC (Bova et al., 1998; Dolci et al., 2003), suggesting an important role in mediating daily changes in hippocampal cell morphology and connectivity.

As with suppression of neurogenesis, circadian disruption negatively impacts synaptic morphology. Chronically phase-shifting mice, through housing in a 20-h 10:10 LD cycle, for example, reduces dendritic length and complexity in the prelimbic prefrontal cortex, in addition to disrupting metabolic and temperature rhythms. Additionally, this manipulation impairs the ability to relearn a task, while sparing initial learning, suggesting a reduction in behavioral flexibility (Karatsoreos, Bhagat, Bloss, Morrison, \& McEwen, 2011). Likewise, dim light exposure at night has recently been shown to disrupt the circadian system (Fonken, Aubrecht, Meléndez-Fernández, Weil, \& Nelson, 2013; Fonken, Kitsmiller, Smale, \& Nelson, 2012; Shuboni \& Yan, 2010) and reduce dendritic complexity (Bedrosian, Fonken, Walton, Haim, \& Nelson, 2011; Fonken et al., 2012). Siberian hamsters exposed to dim light at night exhibit reduced spine density in CA1, independent of circulating cortisol levels (Bedrosian et al., 2011). Similarly, dim light at night reduces dendritic length in the dentate gyrus and CA1 in the diurnal Nile grass rat (Fonken et al., 2012). However, this manipulation does not impair hippocampal-dependent memory, despite diminishing melatonin and BDNF levels in the HC (Bedrosian et al., 2011; Fonken et al., 2013).

Although research on circadian regulation of synaptic morphology is relatively sparse, evidence to date does suggest a strong circadian component of this system. Rhythmic changes in dendritic complexity and spine density have been observed in rats and Siberian hamsters (Ikeno et al., 2013; Perez-Cruz et al., 2009), and many known regulators of synaptic morphology vary in a circadian fashion (Bova et al., 1998; Dolci et al., 2003; González-Burgos et al., 2007; Liston et al., 2013; RamirezRodriguez et al., 2011). Furthermore, circadian disruption via phase shifts or dim light exposure during the dark phase negatively impacts measures of synaptic complexity across species (Bedrosian et al., 2011; Fonken et al., 2012; Karatsoreos et al., 2011). Circadian influence on synaptic morphology likely underlies at least some of the circadian regulation of learning and memory.

\section{Epigenetic Circadian Modulation in Learning and Memory}

Although it seems clear that the circadian system can influence the number and morphology of neurons to affect learning and memory, long-lasting modification of genomic expression may underlie many of these changes. DNA methylation and histone modification can augment or limit access to regulatory elements by changing the underlying architecture of chromatin, resulting in enhancement or repression of gene expression (Clapier \& Cairns, 2009; Saha, Wittmeyer, \& Cairns, 2006). Both circadian physiology and synaptic plasticity are modulated by the dynamic expression of a variety of genes, suggesting the potential for epigenetic control (Belden \& Dunlap, 2008; Borrelli, Nestler, Allis, \& Sassone-Corsi, 2008; Masri \& Sassone-Corsi, 2010; Sahar \& Sassone-Corsi, 2012; Sweatt, 2009; Figure 6). Consistent with this line of reasoning, clock genes, including Per1, Per2, and Cry 1 exhibit circadian rhythms in histone acetylation at their promoter regions that parallel the rhythmic expression of their respective mRNAs (Crosio, Cermakian, Allis, \& Sassone-Corsi, 2000; Curtis et al., 2004; Etchegaray, Lee, Wade, \& Reppert, 2003; Katada \& Sassone-Corsi, 2010; Nader, Chrousos, \& Kino, 2009; Naruse et al., 2004; Ripperger \& Schibler, 2006). Likewise, a key component of the positive transcriptional loop of the molecular clockwork, CLOCK, has been found to act as a fundamental histone acetyltransferase (HATs) enzyme, enhancing the transcription of clock genes through chromatin remodeling. Furthermore, CLOCK's enzymatic HATs function is necessary for the proper function of the molecular clock (Doi, Hirayama, \& Sassone-Corsi, 2006; Hirayama et al., 2007). The NAD+-dependent protein deacetylase, SIRT1, acts to oppose CLOCK HAT activity, repressing transcription promoted by the CLOCK:BMAL1 complex by binding the heterodimer and promoting deacetylation (Asher et al., 2008; Nakahata et al., 2008). With respect to learning and memory, SIRT1 has been implicated in synaptic plasticity; deficiencies in SIRT1 result in the down regulation of phosphorylated CREB and BDNF, important regulators of synaptic plasticity previ- 


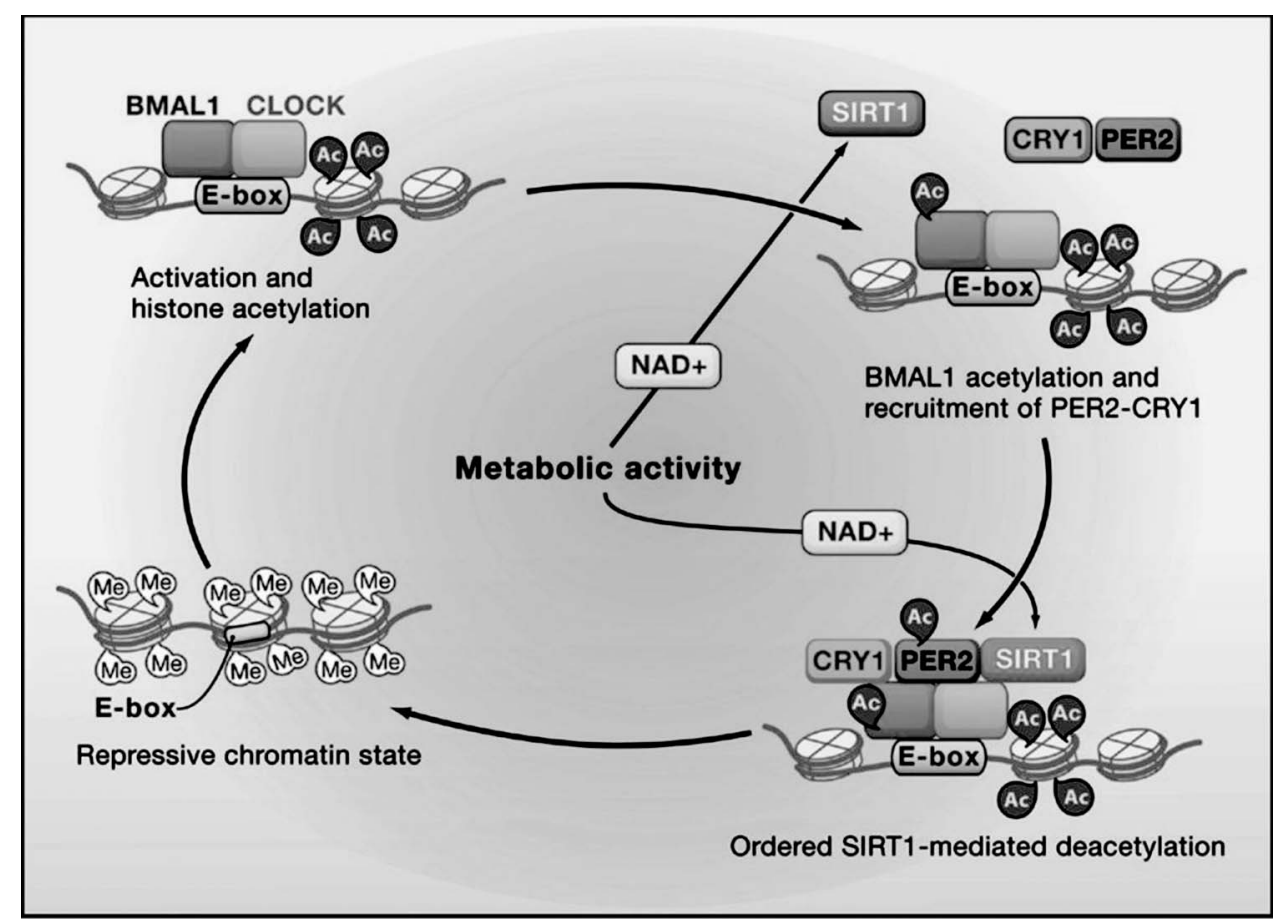

Figure 6. Epigenetic regulation by clock genes. During the activation phase, CLOCK-BMAL1 is associated with the E-box promoter element and CLOCK mediates acetylation of histone tails. BMAL1 then becomes acetylated and recruits PER2-CRY1. PER2 is acetylated and curtails the activation phase. Systematic NAD ${ }^{+}$dependent deacetylation by SIRT of histones, BMAL1, and finally PER2 facilitates the establishment of a repressive chromatin state. For simplicity, SIRT1 is shown only when active. From "SIRT1 is a Circadian Deacetylase for Core Clock Components," by W. Belden and J. Dunlap, Cell, 134, p. 213. Copyright 2008 by Elsevier Inc. Adapted with permission.

ously described (Gao et al., 2010). SIRT1 knockout animals also exhibit deficits in hippocampal-dependent memory tasks (Michán et al., 2010). Although correlative, these findings underscore that there is enormous opportunity to investigate putative circadian-driven epigenetic modifications participating in learning and memory.

\section{Conclusions}

It is clear that some forms of learning and memory show circadian modulation, both in terms of when memories can be activated, and in terms of when they can be most effectively made. Though many forms of learning share these properties, the bulk of extant evidence points to hippocampal learning as particularly subject to circadian influence. This modulation may come from the $\mathrm{SCN}$, but most likely involves input from multiple oscillators, including the $\mathrm{OB}, \mathrm{FEO}$, and the HC itself. Misalignment between the environment or SCN and the other oscillatory systems disrupts acquisition and recall more profoundly than loss of rhythmicity, suggesting nonredundant roles for encoding and storing time-ofday information (e.g., the SCN might encode time of day, whereas the $\mathrm{HC}$ recalls this information, with $\mathrm{SCN}-\mathrm{HC}$ misalignment leading to recall errors).

The HC has multiple levels at which it could potentially both encode time of day into new memories, and exhibit time-of-day modulation in encoding and recall efficiency. The HC shows circadian rhythms in neurogenesis, and the magnitude of neurogenesis correlates with learning behavior. The HC also shows rhythms in clock genes, which both influence and, in turn, are influenced by, central cell-signaling cascades (e.g., cAMP, MAPK). These cascades can affect cellular behavior in the form of receptor expression or synaptic remodeling, and can affect epigenetic regulation of gene expression, potentially enabling (or at least influencing) these cellular changes. These different levels of circadian leverage on hippocampal function almost certainly overlap, complicating the dissection of any one particular piece or even level. And many of these leverage points are also influenced by hormonal signals (e.g., CORT, melatonin), adding still more complexity to the web of processes influencing daily modulation of learning and memory (Figure 7). Finally, differences in temporal niche (across species or even life stages within species) no doubt drive how and when learning and memory change across the day.

Because of the breadth of systems involved in this circadian modulation of learning and memory, many opportunities exist for interested researchers. For example, most studies on the circadian control of learning, memory, and recall have been performed in nocturnal rodents. Given that light exposure can cause anxiety in nocturnal rodents, and that fear and anxiety can affect memory, specific lighting conditions could be confounding in a number of the studies reviewed here. In addition, to know if an effect is truly circadian, as opposed to light-dark driven, tests must be run in 


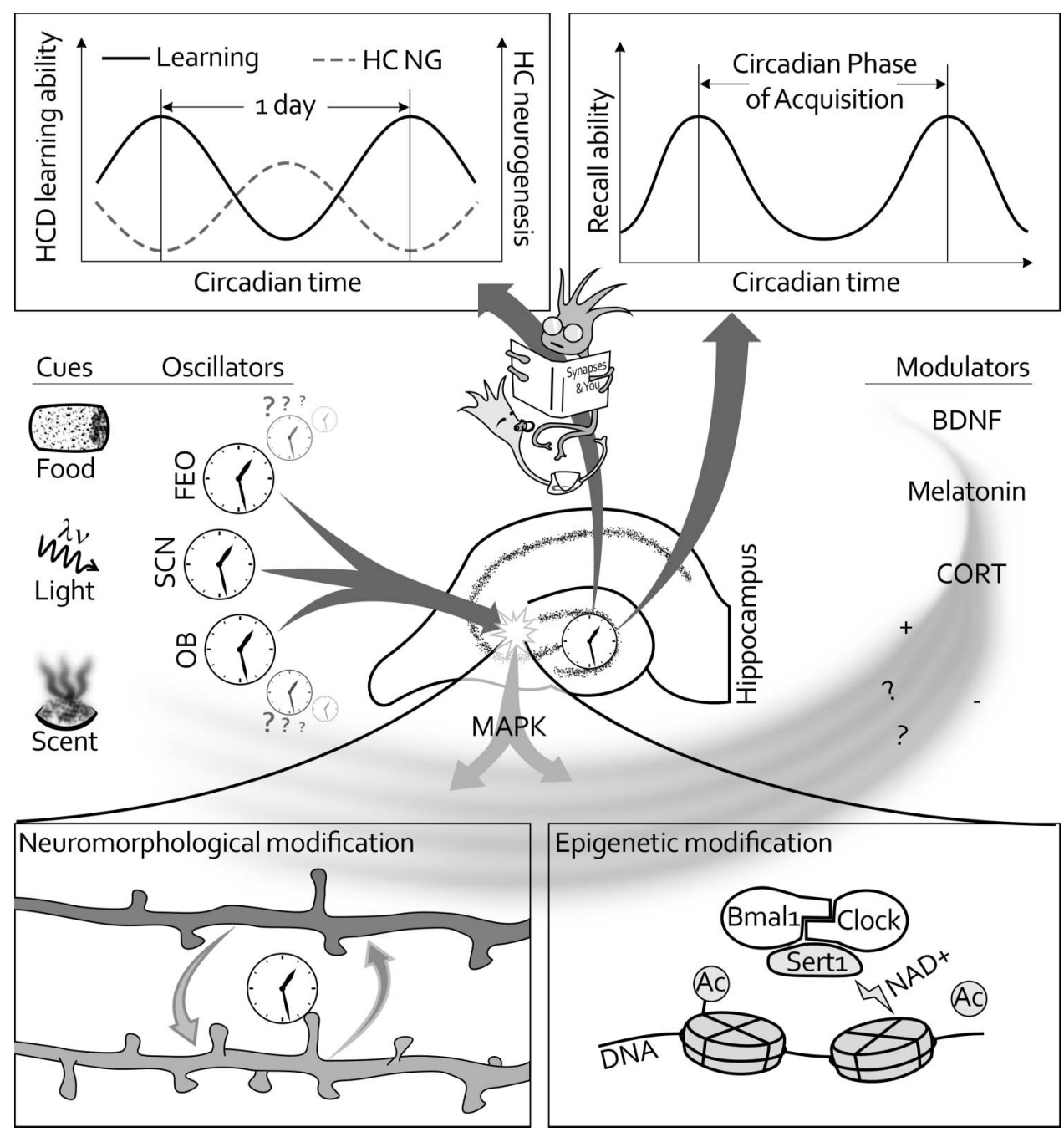

Figure 7. Circadian modulation of learning and memory in the hippocampus (HC), at anatomical, physiological, cellular/molecular, and epigenetic levels. Hippocampal dependent (HCD) learning shows circadian oscillations in acquisition (top left). HCD learning shows circadian rhythms of recall following acquisition, with peaks $24 \mathrm{~h}$ periodically after acquisition (top right). Numerous oscillators likely contribute time stamps to mark time-of-day as part of the context of these memories (left; food entrainable oscillator: FEO; suprachiasmatic nucleus: SCN; olfactory bulb: OB), which manifest in the HC (center). The HC itself shows circadian rhythms of clock genes and cell-signal cascades (e.g., MAPK, center), synaptic remodeling (bottom left), epigenetic remodeling (bottom right), neurogenesis (NG) and neuroprotection (center), all underpinned by myriad interacting signaling pathways (right), including, but not limited to, brain-derived neurotrophic factor (BDNF), melatonin, and glucocorticoids (CORT). How all these pathways interact, and which are necessary or sufficient for specific circadian-based learning and memory effects, remains to be unraveled.

constant conditions appropriate to the species (e.g., $<1$ lux red light for mice or rats) - only a subset of the work presented here was conducted under such conditions, precluding the ability to dissociate "circadian" versus "time of day" effects. Thus, speciesspecific lighting controls should be taken into account to disambiguate such potential confounds in future work. Species and strain differences should also be explored, with greater consideration of species other than nocturnal rodents. Comparisons with other taxa and organisms occupying other temporal niches will yield important insights. Is there a consistent phase relative to activity that shows the greatest learning potential, and if so, what is the func- tion? Are there life histories or temporal niches that tend to promote greater amplitude differences in circadian rhythmicity of learning and memory?

In addition to questions of behavioral differentiation of species, task, and niche, there are many open questions about the underlying neural architecture responsible for circadian control of such patterns. There is expansive work on "state dependent" memory systems, and perhaps "time of day" should be explored as a "state" variable within that infrastructure. In addition, the roles and redundancies of multiple oscillatory systems influencing memory must be studied systematically, at multiple levels of analysis, to be 
disambiguated. For instance, can the OB time stamp new memories under normal circumstances, or only in cases in which the $\mathrm{SCN}$ is not providing circadian information (due to ablation, etc.)? Is the time stamp recalled by circadian information locally in the $\mathrm{HC}$ or through communications from upstream systems? If the former possibility, then why does alignment across oscillators enhance recall? How many layers of redundant (aligned) time-ofday information are needed for optimal recall, and is it dependent on the nature of the task (e.g., OB for scent)?

Finally, given the apparent dominance of hippocampaldependent paradigms used to test learning, careful planning of experiments using strictly HC-independent tasks would allow for understanding the generality of circadian timing in learning and help eliminate some of the seeming paradoxes present in the literature currently. With so many new techniques being developed to gather and mine data more thoroughly than ever, one thing at least is clear: The time for learning about these systems is now.

\section{References}

Abe, K., Kroning, J., Greer, M. A., \& Critchlow, V. (1979). Effects of destruction of the suprachiasmatic nuclei on the circadian rhythms in plasma corticosterone, body temperature, feeding and plasma thyrotropin. Neuroendocrinology, 29, 119-131. doi:10.1159/000122913

Albrecht, U., Sun, Z. S., Eichele, G., \& Lee, C. C. (1997). A differential response of two putative mammalian circadian regulators, mper1 and mper2, to light. Cell, 91, 1055-1064. doi:10.1016/S00928674(00)80495-X

Ambrogini, P., Cuppini, R., Cuppini, C., Ciaroni, S., Cecchini, T., Ferri, P., ... Del Grande, P. (2000). Spatial learning affects immature granule cell survival in adult rat dentate gyrus. Neuroscience Letters, 286, 21-24. doi:10.1016/S0304-3940(00)01074-0

Ambrogini, P., Orsini, L., Mancini, C., Ferri, P., Barbanti, I., \& Cuppini, R. (2002). Persistently high corticosterone levels but not normal circadian fluctuations of the hormone affect cell proliferation in the adult rat dentate gyrus. Neuroendocrinology, 76, 366-372. doi:10.1159/ 000067581

Amir, S., Harbour, V. L., \& Robinson, B. (2006). Pinealectomy does not affect diurnal PER2 expression in the rat limbic forebrain. Neuroscience Letters, 399, 147-150. doi:10.1016/j.neulet.2006.01.041

Anagnostaras, S. G., Gale, G. D., \& Fanselow, M. S. (2001). Hippocampus and contextual fear conditioning: Recent controversies and advances. Hippocampus, 11, 8-17. doi:10.1002/1098-1063(2001)11:1<8::AIDHIPO1015>3.0.CO;2-7

Antle, M. C., \& Silver, R. (2009). Neural basis of timing and anticipatory behaviors. European Journal of Neuroscience, 30, 1643-1649. doi: 10.1111/j.1460-9568.2009.06959.x

Antoniadis, E. A., Ko, C. H., Ralph, M. R., \& McDonald, R. J. (2000). Circadian rhythms, aging and memory. Behavioural Brain Research, 114, 221-233. doi:10.1016/S0166-4328(00)00290-4

Antoun, G., Bouchard-Cannon, P., Cannon, P. B., \& Cheng, H.-Y. M. (2012). Regulation of MAPK/ERK signaling and photic entrainment of the suprachiasmatic nucleus circadian clock by Raf kinase inhibitor protein. The Journal of Neuroscience: The Official Journal of the Society for Neuroscience, 32, 4867-4877. doi:10.1523/JNEUROSCI.5650-11 .2012

Aragona, B. J., Curtis, J. T., Davidson, A. J., Wang, Z., \& Stephan, F. K. (2002). Behavioral and neurochemical investigation of circadian timeplace learning in the rat. Journal of Biological Rhythms, 17, 330-344. doi: $10.1177 / 074873002129002636$

Asher, G., Gatfield, D., Stratmann, M., Reinke, H., Dibner, C., Kreppel, F., ... Schibler, U. (2008). SIRT1 regulates circadian clock gene expression through PER2 deacetylation. Cell, 134, 317-328. doi:10.1016/j.cell .2008 .06 .050

Athos, J., Impey, S., Pineda, V. V., Chen, X., \& Storm, D. R. (2002). Hippocampal CRE-mediated gene expression is required for contextual memory formation. Nature Neuroscience, 5, 1119-1120. doi:10.1038/ nn951

Atkins, N., Jr., Mitchell, J. W., Romanova, E. V., Morgan, D. J., Cominski, T. P., Ecker, J. L., . . Gillette, M. U. (2010). Circadian integration of glutamatergic signals by little SAAS in novel suprachiasmatic circuits. PLoS One, 5, e12612. doi:10.1371/journal.pone.0012612

Barnes, C. A., McNaughton, B. L., Goddard, G. V., Douglas, R. M., \& Adamec, R. (1977, July 1). Circadian rhythm of synaptic excitability in rat and monkey central nervous system. Science, 197, 91-92. doi: 10.1126/science. 194313

Bast, T., Zhang, W.-N., \& Feldon, J. (2003). Dorsal hippocampus and classical fear conditioning to tone and context in rats: Effects of local NMDA-receptor blockade and stimulation. Hippocampus, 13, 657-675. doi:10.1002/hipo.10115

Bedrosian, T. A., Fonken, L. K., Walton, J. C., Haim, A., \& Nelson, R. J. (2011). Dim light at night provokes depression-like behaviors and reduces CA1 dendritic spine density in female hamsters. Psychoneuroendocrinology, 36, 1062-1069. doi:10.1016/j.psyneuen.2011.01.004

Belden, W. J., \& Dunlap, J. C. (2008). SIRT1 is a circadian deacetylase for core clock components. Cell, 134, 212-214. doi:10.1016/j.cell.2008.07 .010

Best, J. D., Maywood, E. S., Smith, K. L., \& Hastings, M. H. (1999). Rapid resetting of the mammalian circadian clock. The Journal of Neuroscience: The Official Journal of the Society for Neuroscience, 19, 828835.

Bialik, R. J., Pappas, B. A., \& Roberts, D. C. (1984). Deficits in conditioned avoidance responding following adrenalectomy and central norepinephrine depletion are dependent on postsurgical recovery period and phase of the diurnal cycle. Behavioral Neuroscience, 98, 847-857. doi:10.1037/0735-7044.98.5.847

Biebach, H., Falk, H., \& Krebs, J. R. (1991). The effect of constant light and phase shifts on a learned time-place association in garden warblers (Sylvia borin): Hourglass or circadian clock? Journal of Biological Rhythms, 6, 353-365. doi:10.1177/074873049100600406

Bolles, R. C., \& Stokes, L. W. (1965). Rat's anticipation of diurnal and a-diurnal feeding. Journal of Comparative and Physiological Psychology, 60, 290-294. doi:10.1037/h0022308

Borgs, L., Beukelaers, P., Vandenbosch, R., Belachew, S., Nguyen, L., \& Malgrange, B. (2009). Cell "circadian" cycle: New role for mammalian core clock genes. Cell Cycle (Georgetown, Tex.), 8, 832-837. doi: 10.4161/cc.8.6.7869

Borgs, L., Beukelaers, P., Vandenbosch, R., Nguyen, L., Moonen, G., Maquet, P., . . . Malgrange, B. (2009). Period 2 regulates neural stem/ progenitor cell proliferation in the adult hippocampus. BMC Neuroscience, 10, 30. doi:10.1186/1471-2202-10-30

Borrelli, E., Nestler, E. J., Allis, C. D., \& Sassone-Corsi, P. (2008). Decoding the epigenetic language of neuronal plasticity. Neuron, 60 961-974. doi:10.1016/j.neuron.2008.10.012

Bova, R., Micheli, M. R., Qualadrucci, P., \& Zucconi, G. G. (1998). BDNF and trkB mRNAs oscillate in rat brain during the light-dark cycle. Brain Research: Molecular Brain Research, 57, 321-324. doi:10.1016/S0169328X(98)00092-8

Bridge, D. J., \& Paller, K. A. (2012). Neural correlates of reactivation and retrieval-induced distortion. The Journal of Neuroscience, 32, 12144 12151. doi:10.1523/JNEUROSCI.1378-12.2012

Buijs, R. M., Kalsbeek, A., van der Woude, T. P., van Heerikhuize, J. J., \& Shinn, S. (1993). Suprachiasmatic nucleus lesion increases corticosterone secretion. The American Journal of Physiology, 264, R1186R1192. 
Butcher, G. Q., Lee, B., Cheng, H.-Y. M., \& Obrietan, K. (2005). Light stimulates MSK1 activation in the suprachiasmatic nucleus via a PACAP-ERK/MAP kinase-dependent mechanism. The Journal of Neuroscience: The Official Journal of the Society for Neuroscience, 25, 5305-5313. doi:10.1523/JNEUROSCI.4361-04.2005

Cain, S. W., Chou, T., \& Ralph, M. R. (2004). Circadian modulation of performance on an aversion-based place learning task in hamsters. Behavioural Brain Research, 150, 201-205. doi:10.1016/j.bbr.2003.07 .00

Cain, S. W., Karatsoreos, I., Gautam, N., Konar, Y., Funk, D., McDonald, R. J., \& Ralph, M. R. (2004). Blunted cortisol rhythm is associated with learning impairment in aged hamsters. Physiology \& Behavior, 82, 339-344. doi:10.1016/j.physbeh.2004.04.004

Cain, S. W., McDonald, R. J., \& Ralph, M. R. (2008). Time stamp in conditioned place avoidance can be set to different circadian phases. Neurobiology of Learning and Memory, 89, 591-594. doi:10.1016/j.nlm 2007.07.011

Cameron, H. A., \& McKay, R. D. (2001). Adult neurogenesis produces a large pool of new granule cells in the dentate gyrus. The Journal of Comparative Neurology, 435, 406-417. doi:10.1002/cne.1040

Carneiro, B. T. S., \& Araujo, J. F. (2012). Food entrainment: Major and recent findings. Frontiers in Behavioral Neuroscience, 6, 83. doi: 10.3389/fnbeh.2012.00083

Caroni, P., Donato, F., \& Muller, D. (2012). Structural plasticity upon learning: Regulation and functions. Nature Reviews Neuroscience, 13, 478-490. doi: $10.1038 / \mathrm{nrn} 3258$

Carr, J. A., \& Wilkie, D. M. (1997). Rats use an ordinal timer in a daily time-place learning task. Journal of Experimental Psychology Animal Behavior Processes, 23, 232-247. doi:10.1037/0097-7403.23.2.232

Cauller, L. J., Boulos, Z., \& Goddard, G. V. (1985). Circadian rhythms in hippocampal responsiveness to perforant path stimulation and their relation to behavioral state. Brain Research, 329, 117-130. doi:10.1016/ 0006-8993(85)90517-7

Chaudhury, D., \& Colwell, C. S. (2002). Circadian modulation of learning and memory in fear-conditioned mice. Behavioural Brain Research, 133, 95-108. doi:10.1016/S0166-4328(01)00471-5

Chaudhury, D., Loh, D. H., Dragich, J. M., Hagopian, A., \& Colwell, C. S. (2008). Select cognitive deficits in vasoactive intestinal peptide deficient mice. BMC Neuroscience, 9, 63. doi:10.1186/1471-2202-9-63

Chaudhury, D., Wang, L. M., \& Colwell, C. S. (2005). Circadian regulation of hippocampal long-term potentiation. Journal of Biological Rhythms, 20, 225-236. doi:10.1177/0748730405276352

Clapier, C. R., \& Cairns, B. R. (2009). The biology of chromatin remodeling complexes. Annual Review of Biochemistry, 78, 273-304. doi: 10.1146/annurev.biochem.77.062706.153223

Clelland, C. D., Choi, M., Romberg, C., Clemenson, G. D., Jr., Fragniere, A., Tyers, P., . . Bussey, T. J. (2009, July 10). A functional role for adult hippocampal neurogenesis in spatial pattern separation. Science, 325, 210-213. doi:10.1126/science.1173215

Coll-Andreu, M., Martí-Nicolovius, M., \& Morgado-Bernal, I. (1991). Facilitation of shuttle-box avoidance by the platform method: Temporal effects. Physiology \& Behavior, 49, 1211-1215. doi:10.1016/00319384(91)90353-P

Collins, D. R., \& Davies, S. N. (1997). Melatonin blocks the induction of long-term potentiation in an N-methyl-D-aspartate independent manner. Brain Research, 767, 162-165. doi:10.1016/S0006-8993(97)00733-6

Corcoran, K. A., \& Maren, S. (2001). Hippocampal inactivation disrupts contextual retrieval of fear memory after extinction. The Journal of Neuroscience, 21, 1720-1726.

Cordero, M. I., Merino, J. J., \& Sandi, C. (1998). Correlational relationship between shock intensity and corticosterone secretion on the establishment and subsequent expression of contextual fear conditioning. Behavioral Neuroscience, 112, 885-891. doi:10.1037/0735-7044.112.4.885
Craig, L. A., \& McDonald, R. J. (2008). Chronic disruption of circadian rhythms impairs hippocampal memory in the rat. Brain Research Bulletin, 76, 141-151. doi:10.1016/j.brainresbull.2008.02.013

Crosio, C., Cermakian, N., Allis, C. D., \& Sassone-Corsi, P. (2000). Light induces chromatin modification in cells of the mammalian circadian clock. Nature Neuroscience, 3, 1241-1247. doi:10.1038/81767

Curtis, A. M., Seo, S., Westgate, E. J., Rudic, R. D., Smyth, E. M., Chakravarti, D., . . . McNamara, P. (2004). Histone acetyltransferasedependent chromatin remodeling and the vascular clock. The Journal of Biological Chemistry, 279, 7091-7097. doi:10.1074/jbc.M311973200

Daan, S. (2000). Learning and circadian behavior. Journal of Biological Rhythms, 15, 296-299. doi:10.1177/074873000129001396

Dana, R. C., \& Martinez, J. L., Jr. (1984). Effect of adrenalectomy on the circadian rhythm of LTP. Brain Research, 308, 392-395. doi:10.1016/ 0006-8993(84)91086-2

Davies, J. A., Navaratnam, V., \& Redfern, P. H. (1974). The effect of phase-shift on the passive avoidance response in rats and the modifying action of chlordiazepoxide. British Journal of Pharmacology, 51, 447451. doi:10.1111/j.1476-5381.1974.tb10681.x

Decker, S., McConnaughey, S., \& Page, T. L. (2007). Circadian regulation of insect olfactory learning. PNAS Proceedings of the National Academy of Sciences of the United States of America, 104, 15905-15910. doi: 10.1073/pnas.0702082104

Deng, W., Aimone, J. B., \& Gage, F. H. (2010). New neurons and new memories: How does adult hippocampal neurogenesis affect learning and memory? Nature Reviews Neuroscience, 11, 339-350. doi:10.1038/ nrn2822

Devan, B. D., Goad, E. H., Petri, H. L., Antoniadis, E. A., Hong, N. S., Ko, C. H., . . . McDonald, R. J. (2001). Circadian phase-shifted rats show normal acquisition but impaired long-term retention of place information in the water task. Neurobiology of Learning and Memory, 75, 51-62. doi:10.1006/nlme.1999.3957

Diamond, D. M., Bennett, M. C., Fleshner, M., \& Rose, G. M. (1992) Inverted-U relationship between the level of peripheral corticosterone and the magnitude of hippocampal primed burst potentiation. Hippocampus, 2, 421-430. doi:10.1002/hipo.450020409

Doi, M., Hirayama, J., \& Sassone-Corsi, P. (2006). Circadian regulator CLOCK is a histone acetyltransferase. Cell, 125, 497-508. doi:10.1016/ j.cell.2006.03.033

Dolci, C., Montaruli, A., Roveda, E., Barajon, I., Vizzotto, L., Grassi Zucconi, G., \& Carandente, F. (2003). Circadian variations in expression of the trkB receptor in adult rat hippocampus. Brain Research, 994, 67-72. doi:10.1016/j.brainres.2003.09.018

Duncan, M. J., Prochot, J. R., Cook, D. H., Tyler Smith, J., \& Franklin, K. M. (2013). Influence of aging on Bmal1 and Per2 expression in extra-SCN oscillators in hamster brain. Brain Research, 1491, 44-53. doi:10.1016/j.brainres.2012.11.008

Dupret, D., Fabre, A., Döbrössy, M. D., Panatier, A., Rodríguez, J. J., Lamarque, S., . . Abrous, D. N. (2007). Spatial learning depends on both the addition and removal of new hippocampal neurons. PLOS Biology, 5, e214. doi:10.1371/journal.pbio.0050214

Dupret, D., Revest, J.-M., Koehl, M., Ichas, F., De Giorgi, F., Costet, P. . . . Piazza, P. V. (2008). Spatial relational memory requires hippocampal adult neurogenesis. PLoS One, 3, e1959. doi:10.1371/journal.pone .0001959

Dziema, H., Oatis, B., Butcher, G. Q., Yates, R., Hoyt, K. R., \& Obrietan, K. (2003). The ERK/MAP kinase pathway couples light to immediateearly gene expression in the suprachiasmatic nucleus. The European Journal of Neuroscience, 17, 1617-1627. doi:10.1046/j.1460-9568.2003 02592.x

Eckel-Mahan, K. L. (2012). Circadian oscillations within the hippocampus support memory formation and persistence. Frontiers in Molecular Neuroscience, 5, 46. doi:10.3389/fnmol.2012.00046 
Eckel-Mahan, K. L., Phan, T., Han, S., Wang, H., Chan, G. C. K., Scheiner, Z. S., \& Storm, D. R. (2008). Circadian oscillation of hippocampal MAPK activity and cAmp: Implications for memory persistence. Nature Neuroscience, 11, 1074-1082. doi:10.1038/nn.2174

El-Sherif, Y., Tesoriero, J., Hogan, M. V., \& Wieraszko, A. (2003). Melatonin regulates neuronal plasticity in the hippocampus. Journal of Neuroscience Research, 72, 454-460. doi:10.1002/jnr.10605

Epp, J. R., Spritzer, M. D., \& Galea, L. A. M. (2007). Hippocampusdependent learning promotes survival of new neurons in the dentate gyrus at a specific time during cell maturation. Neuroscience, 149, 273-285. doi:10.1016/j.neuroscience.2007.07.046

Etchegaray, J.-P., Lee, C., Wade, P. A., \& Reppert, S. M. (2003, January 9). Rhythmic histone acetylation underlies transcription in the mammalian circadian clock. Nature, 421, 177-182. doi:10.1038/nature01314

Farioli-Vecchioli, S., Saraulli, D., Costanzi, M., Pacioni, S., Cinà, I., Aceti, M., . . . Tirone, F. (2008). The timing of differentiation of adult hippocampal neurons is crucial for spatial memory. PLoS Biology, 6, e246. doi:10.1371/journal.pbio.0060246

Fekete, M., Van Ree, J. M., \& De Wied, D. (1986). The ACTH-(4-9) analog ORG 2766 and desglycinamide9-(Arg8)-vasopressin reverse the retrograde amnesia induced by disrupting circadian rhythms in rats. Peptides, 7, 563-568. doi:10.1016/0196-9781(86)90027-6

Fekete, M., van Ree, J. M., Niesink, R. J., \& de Wied, D. (1985). Disrupting circadian rhythms in rats induces retrograde amnesia. Physiology \& Behavior, 34, 883-887. doi:10.1016/0031-9384(85)90008-3

Fernandez, R. I., Lyons, L. C., Levenson, J., Khabour, O., \& Eskin, A. (2003). Circadian modulation of long-term sensitization in Aplysia. PNAS Proceedings of the National Academy of Sciences of the United States of America, 100, 14415-14420. doi:10.1073/pnas.2336172100

Filipini, D., Gijsbers, K., Birmingham, M. K., \& Dubrovsky, B. (1991). Effects of adrenal steroids and their reduced metabolites on hippocampal long-term potentiation. The Journal of Steroid Biochemistry and Molecular Biology, 40, 87-92. doi:10.1016/0960-0760(91)90171-Z

Fonken, L. K., Aubrecht, T. G., Meléndez-Fernández, O. H., Weil, Z. M., \& Nelson, R. J. (2013). Dim light at night disrupts molecular circadian rhythms and increases body weight. Journal of Biological Rhythms, 28, 262-271. doi:10.1177/0748730413493862

Fonken, L. K., Kitsmiller, E., Smale, L., \& Nelson, R. J. (2012). Dim nighttime light impairs cognition and provokes depressive-like responses in a diurnal rodent. Journal of Biological Rhythms, 27, 319327. doi: $10.1177 / 0748730412448324$

Frohardt, R. J., Guarraci, F. A., \& Bouton, M. E. (2000). The effects of neurotoxic hippocampal lesions on two effects of context after fear extinction. Behavioral Neuroscience, 114, 227-240. doi:10.1037/07357044.114.2.227

Fujihara, H., Sei, H., Morita, Y., Ueta, Y., \& Morita, K. (2003). Short-term sleep disturbance enhances brain-derived neurotrophic factor gene expression in rat hippocampus by acting as internal stressor. Journal of Molecular Neuroscience: MN, 21, 223-232.

Fujioka, A., Fujioka, T., Tsuruta, R., Izumi, T., Kasaoka, S., \& Maekawa, T. (2011). Effects of a constant light environment on hippocampal neurogenesis and memory in mice. Neuroscience Letters, 488, 41-44. doi:10.1016/j.neulet.2010.11.001

Ganguly, S., Coon, S. L., \& Klein, D. C. (2002). Control of melatonin synthesis in the mammalian pineal gland: The critical role of serotonin acetylation. Cell and Tissue Research, 309, 127-137. doi:10.1007/ s00441-002-0579-y

Gao, J., Wang, W.-Y., Mao, Y.-W., Gräff, J., Guan, J.-S., Pan, L., . . Tsai, L.-H. (2010, August 26). A novel pathway regulates memory and plasticity via SIRT1 and miR-134. Nature, 466, 1105-1109. doi: 10.1038/nature09271

Garren, M. V., Sexauer, S. B., \& Page, T. L. (2013). Effect of circadian phase on memory acquisition and recall: Operant conditioning vs. clas- sical conditioning. PLoS One, 8, e58693. doi:10.1371/journal.pone 0058693

Gartside, S. E., Leitch, M. M., McQuade, R., \& Swarbrick, D. J. (2003). Flattening the glucocorticoid rhythm causes changes in hippocampal expression of messenger RNAs coding structural and functional proteins: Implications for aging and depression. Neuropsychopharmacology: Official Publication of the American College of Neuropsychopharmacology, 28, 821-829. doi:10.1038/sj.npp.1300104

Gerstner, J. R., Lyons, L. C., Wright, K. P., Jr., Loh, D. H., Rawashdeh, O., Eckel-Mahan, K. L., \& Roman, G. W. (2009). Cycling behavior and memory formation. The Journal of Neuroscience: The Official Journal of the Society for Neuroscience, 29, 12824-12830. doi:10.1523/ JNEUROSCI.3353-09.2009

Gery, S., Komatsu, N., Baldjyan, L., Yu, A., Koo, D., \& Koeffler, H. P. (2006). The circadian gene per1 plays an important role in cell growth and DNA damage control in human cancer cells. Molecular Cell, 22, 375-382. doi:10.1016/j.molcel.2006.03.038

Ghiselli, W. B., \& Patton, R. A. (1976). Diurnal variation in performance of free-operant avoidance behavior of rats. Psychological Reports, 38, 83-90. doi:10.2466/pr0.1976.38.1.83

Gibson, E. M., Wang, C., Tjho, S., Khattar, N., \& Kriegsfeld, L. J. (2010). Experimental "jet lag" inhibits adult neurogenesis and produces longterm cognitive deficits in female hamsters. PLoS One, 5, e15267. doi: 10.1371/journal.pone.0015267

Gilhooley, M. J., Pinnock, S. B., \& Herbert, J. (2011). Rhythmic expression of per1 in the dentate gyrus is suppressed by corticosterone: Implications for neurogenesis. Neuroscience Letters, 489, 177-181. doi: 10.1016/j.neulet.2010.12.011

Goergen, E. M., Bagay, L. A., Rehm, K., Benton, J. L., \& Beltz, B. S. (2002). Circadian control of neurogenesis. Journal of Neurobiology, 53 , 90-95. doi:10.1002/neu.10095

Gomez, F., Chapleur, M., Fernette, B., Burlet, C., Nicolas, J. P., \& Burlet, A. (1997). Arginine vasopressin (AVP) depletion in neurons of the suprachiasmatic nuclei affects the AVP content of the paraventricular neurons and stimulates adrenocorticotrophic hormone release. Journal of Neuroscience Research, 50, 565-574. doi:10.1002/(SICI)10974547(19971115)50:4<565::AID-JNR7>3.0.CO;2-C

González-Burgos, I., Letechipía-Vallejo, G., López-Loeza, E., Moralí, G., \& Cervantes, M. (2007). Long-term study of dendritic spines from hippocampal CA1 pyramidal cells, after neuroprotective melatonin treatment following global cerebral ischemia in rats. Neuroscience Letters, 423, 162-166. doi:10.1016/j.neulet.2007.06.050

Gould, E., Beylin, A., Tanapat, P., Reeves, A., \& Shors, T. J. (1999). Learning enhances adult neurogenesis in the hippocampal formation. Nature Neuroscience, 2, 260-265. doi:10.1038/6365

Gould, J. L. (1987). Honey bees store learned flower-landing behaviour according to time of day. Animal Behaviour, 35, 1579-1581. doi: 10.1016/S0003-3472(87)80038-6

Granados-Fuentes, D., Tseng, A., \& Herzog, E. D. (2006). A circadian clock in the olfactory bulb controls olfactory responsivity. The Journal of Neuroscience: The Official Journal of the Society for Neuroscience, 26, 12219-12225. doi:10.1523/JNEUROSCI.3445-06.2006

Gritton, H. J., Kantorowski, A., Sarter, M., \& Lee, T. M. (2012). Bidirectional interactions between circadian entrainment and cognitive performance. Learning \& Memory (Cold Spring Harbor, N.Y.), 19, 126-141. doi:10.1101/lm.023499.111

Gritton, H. J., Stasiak, A. M., Sarter, M., \& Lee, T. M. (2013). Cognitive performance as a zeitgeber: Cognitive oscillators and cholinergic modulation of the SCN entrain circadian rhythms. PLoS One, 8, e56206. doi:10.1371/journal.pone.0056206

Gritton, H. J., Sutton, B. C., Martinez, V., Sarter, M., \& Lee, T. M. (2009). Interactions between cognition and circadian rhythms: Attentional demands modify circadian entrainment. Behavioral Neuroscience, 123, 937-948. doi:10.1037/a0017128 
Guzman-Marin, R., Bashir, T., Suntsova, N., Szymusiak, R., \& McGinty, D. (2007). Hippocampal neurogenesis is reduced by sleep fragmentation in the adult rat. Neuroscience, 148, 325-333. doi:10.1016/j.neuroscience .2007 .05 .030

Guzman-Marin, R., Suntsova, N., Bashir, T., Nienhuis, R., Szymusiak, R., \& McGinty, D. (2008). Rapid eye movement sleep deprivation contributes to reduction of neurogenesis in the hippocampal dentate gyrus of the adult rat. Sleep: Journal of Sleep and Sleep Disorders Research, 31, $167-175$.

Guzman-Marin, R., Suntsova, N., Bashir, T., Szymusiak, R., \& McGinty, D. (2007). Cell proliferation in the dentate gyrus of the adult rat fluctuates with the light-dark cycle. Neuroscience Letters, 422, 198-201. doi:10.1016/j.neulet.2007.06.022

Guzman-Marin, R., Suntsova, N., Methippara, M., Greiffenstein, R., Szymusiak, R., \& McGinty, D. (2005). Sleep deprivation suppresses neurogenesis in the adult hippocampus of rats. The European Journal of Neuroscience, 22, 2111-2116. doi:10.1111/j.1460-9568.2005.04376.x

Guzmán-Marín, R., Suntsova, N., Stewart, D. R., Gong, H., Szymusiak, R., \& McGinty, D. (2003). Sleep deprivation reduces proliferation of cells in the dentate gyrus of the hippocampus in rats. The Journal of Physiology, 549, 563-571. doi:10.1113/jphysiol.2003.041665

Guzman-Marin, R., Ying, Z., Suntsova, N., Methippara, M., Bashir, T., Szymusiak, R., . . McGinty, D. (2006). Suppression of hippocampal plasticity-related gene expression by sleep deprivation in rats. The Journal of Physiology, 575, 807-819. doi:10.1113/jphysiol.2006.115287

Hairston, I. S., Little, M. T. M., Scanlon, M. D., Barakat, M. T., Palmer, T. D., Sapolsky, R. M., \& Heller, H. C. (2005). Sleep restriction suppresses neurogenesis induced by hippocampus-dependent learning. Journal of Neurophysiology, 94, 4224-4233. doi:10.1152/jn.00218 .2005

Harris, K. M., \& Teyler, T. J. (1983). Age differences in a circadian influence on hippocampal LTP. Brain Research, 261, 69-73. doi: 10.1016/0006-8993(83)91284-2

Hauber, W., \& Bareiss, A. (2001). Facilitative effects of an adenosine A1/A2 receptor blockade on spatial memory performance of rats: Selective enhancement of reference memory retention during the light period. Behavioural Brain Research, 118, 43-52. doi:10.1016/S01664328(00)00307-7

Hirayama, J., Sahar, S., Grimaldi, B., Tamaru, T., Takamatsu, K., Nakahata, Y., \& Sassone-Corsi, P. (2007, December 13). CLOCK-mediated acetylation of BMAL1 controls circadian function. Nature, 450, 10861090. doi: $10.1038 /$ nature 06394

Hoffmann, H., \& Balschun, D. (1992). Circadian differences in maze performance of c57bl/6 OLA mice. Retrieved from https://lirias .kuleuven.be/handle/123456789/125811

Holloway, F. A., \& Sturgis, R. D. (1976). Periodic decrements in retrieval of the memory of nonreinforcement as reflected in resistance to extinction. Journal of Experimental Psychology: Animal Behavior Processes, 2, 335-341. doi:10.1037/0097-7403.2.4.335

Holloway, F. A., \& Wansley, R. (1973a, April 13). Multiphasic retention deficits at periodic intervals after passive-avoidance learning. Science, 180, 208-210. doi:10.1126/science.180.4082.208

Holloway, F. A., \& Wansley, R. A. (1973b). Multiple retention deficits at periodic intervals after active and passive avoidance learning. Behavioral Biology, 9, 1-14. doi:10.1016/S0091-6773(73)80164-6

Holmes, M. M., Galea, L. A. M., Mistlberger, R. E., \& Kempermann, G. (2004). Adult hippocampal neurogenesis and voluntary running activity: Circadian and dose-dependent effects. Journal of Neuroscience Research, 76, 216-222. doi:10.1002/jnr.20039

Holmes, M. M., \& Mistlberger, R. E. (2000). Food anticipatory activity and photic entrainment in food-restricted BALB/c mice. Physiology \& Behavior, 68, 655-666. doi:10.1016/S0031-9384(99)00231-0
Hunsicker, J. P., \& Mellgren, R. L. (1977). Multiple deficits in the retention of an appetitively motivated behavior across a $24-\mathrm{h}$ period in rats. Animal Learning \& Behavior, 5, 14-16. doi:10.3758/BF03209124

Ikeno, T., Weil, Z. M., \& Nelson, R. J. (2013). Photoperiod affects the diurnal rhythm of hippocampal neuronal morphology of Siberian hamsters. Chronobiology International, 30, 1089-1100. doi:10.3109/ 07420528.2013.800090

Jang, S.-W., Liu, X., Pradoldej, S., Tosini, G., Chang, Q., Iuvone, P. M., \& Ye, K. (2010). N-acetylserotonin activates TrkB receptor in a circadian rhythm. PNAS Proceedings of the National Academy of Sciences of the United States of America, 107, 3876-3881. doi:10.1073/pnas .0912531107

Jilg, A., Lesny, S., Peruzki, N., Schwegler, H., Selbach, O., Dehghani, F., \& Stehle, J. H. (2010). Temporal dynamics of mouse hippocampal clock gene expression support memory processing. Hippocampus, 20, 377388. doi:10.1002/hipo.20637

Joëls, M., \& Krugers, H. J. (2007). LTP after stress: Up or down? Neural Plasticity, 2007, 93202. doi:10.1155/2007/93202

Junek, A., Rusak, B., \& Semba, K. (2010). Short-term sleep deprivation may alter the dynamics of hippocampal cell proliferation in adult rats Neuroscience, 170, 1140-1152. doi:10.1016/j.neuroscience.2010.08 .018

Kalsbeek, A., Buijs, R. M., van Heerikhuize, J. J., Arts, M., \& van der Woude, T. P. (1992). Vasopressin-containing neurons of the suprachiasmatic nuclei inhibit corticosterone release. Brain Research, 580, 6267. doi:10.1016/0006-8993(92)90927-2

Kalsbeek, A., van Heerikhuize, J. J., Wortel, J., \& Buijs, R. M. (1996). A diurnal rhythm of stimulatory input to the hypothalamo-pituitary-adrenal system as revealed by timed intrahypothalamic administration of the vasopressin V1 antagonist. The Journal of Neuroscience: The Official Journal of the Society for Neuroscience, 16, 5555-5565.

Karatsoreos, I. N., Bhagat, S., Bloss, E. B., Morrison, J. H., \& McEwen, B. S. (2011). Disruption of circadian clocks has ramifications for metabolism, brain, and behavior. PNAS Proceedings of the National Academy of Sciences of the United States of America, 108, 1657-1662. doi:10.1073/pnas.1018375108

Katada, S., \& Sassone-Corsi, P. (2010). The histone methyltransferase MLL1 permits the oscillation of circadian gene expression. Nature Structural \& Molecular Biology, 17, 1414-1421. doi:10.1038/nsmb .1961

Kelleher, R. J., 3rd, Govindarajan, A., Jung, H.-Y., Kang, H., \& Tonegawa, S. (2004). Translational control by MAPK signaling in long-term synaptic plasticity and memory. Cell, 116, 467-479. doi:10.1016/S00928674(04)00115-1

Kelliher, P., Connor, T. J., Harkin, A., Sanchez, C., Kelly, J. P., \& Leonard, B. E. (2000). Varying responses to the rat forced-swim test under diurnal and nocturnal conditions. Physiology \& Behavior, 69, 531-539. doi: 10.1016/S0031-9384(00)00213-4

Kelly, A., Laroche, S., \& Davis, S. (2003). Activation of mitogen-activated protein kinase/extracellular signal-regulated kinase in hippocampal circuitry is required for consolidation and reconsolidation of recognition memory. The Journal of Neuroscience: The Official Journal of the Society for Neuroscience, 23, 5354-5360.

Kimiwada, T., Sakurai, M., Ohashi, H., Aoki, S., Tominaga, T., \& Wada, K. (2009). Clock genes regulate neurogenic transcription factors, including NeuroD1, and the neuronal differentiation of adult neural stem/ progenitor cells. Neurochemistry International, 54, 277-285. doi: 10.1016/j.neuint.2008.12.005

Ko, C. H., McDonald, R. J., \& Ralph, M. R. (2003). The suprachiasmatic nucleus is not required for temporal gating of performance on a rewardbased learning and memory task. Biological Rhythm Research, 34, 177-192. doi:10.1076/brhm.34.2.177.14493 
Ko, C. H., \& Takahashi, J. S. (2006). Molecular components of the mammalian circadian clock. Human Molecular Genetics, 15(Suppl 2), R271-R277. doi:10.1093/hmg/dd1207

Kochman, L. J., Weber, E. T., Fornal, C. A., \& Jacobs, B. L. (2006). Circadian variation in mouse hippocampal cell proliferation. Neuroscience Letters, 406, 256-259. doi:10.1016/j.neulet.2006.07.058

Kole, M. H., Koolhaas, J. M., Luiten, P. G., \& Fuchs, E. (2001). Highvoltage-activated $\mathrm{Ca} 2+$ currents and the excitability of pyramidal neurons in the hippocampal CA3 subfield in rats depend on corticosterone and time of day. Neuroscience Letters, 307, 53-56. doi:10.1016/S03043940(01)01926-7

Koleske, A. J. (2013). Molecular mechanisms of dendrite stability. Nature Reviews Neuroscience, 14, 536-550. doi:10.1038/nrn3486

Kott, J., Leach, G., \& Yan, L. (2012). Direction-dependent effects of chronic "jet-lag" on hippocampal neurogenesis. Neuroscience Letters, 515, 177-180. doi:10.1016/j.neulet.2012.03.048

Lamont, E. W., Robinson, B., Stewart, J., \& Amir, S. (2005). The central and basolateral nuclei of the amygdala exhibit opposite diurnal rhythms of expression of the clock protein Period2. PNAS Proceedings of the National Academy of Sciences of the United States of America, 102, 4180-4184. doi:10.1073/pnas.0500901102

Leuner, B., Mendolia-Loffredo, S., Kozorovitskiy, Y., Samburg, D., Gould, E., \& Shors, T. J. (2004). Learning enhances the survival of new neurons beyond the time when the hippocampus is required for memory. The Journal of Neuroscience: The Official Journal of the Society for Neuroscience, 24, 7477-7481. doi:10.1523/JNEUROSCI.0204-04.2004

Lilley, T. R., Wotus, C., Taylor, D., Lee, J. M., \& de la Iglesia, H. O. (2012). Circadian regulation of cortisol release in behaviorally split golden hamsters. Endocrinology, 153, 732-738. doi:10.1210/en.20111624

Lisman, J. (2003). Long-term potentiation: Outstanding questions and attempted synthesis. Philosophical Transactions of the Royal Society of London: Series B: Biological Sciences, 358, 829-842. doi:10.1098/rstb .2002 .1242

Liston, C., Cichon, J. M., Jeanneteau, F., Jia, Z., Chao, M. V., \& Gan, W.-B. (2013). Circadian glucocorticoid oscillations promote learningdependent synapse formation and maintenance. Nature Neuroscience, 16, 698-705. doi:10.1038/nn.3387

Loh, D. H., Navarro, J., Hagopian, A., Wang, L. M., Deboer, T., \& Colwell, C. S. (2010). Rapid changes in the light/dark cycle disrupt memory of conditioned fear in mice. PLoS One, 5, e12546. doi:10.1371/ journal.pone. 0012546

Lonze, B. E., \& Ginty, D. D. (2002). Function and regulation of CREB family transcription factors in the nervous system. Neuron, 35, 605-623. doi:10.1016/S0896-6273(02)00828-0

Lowrey, P. L., Shimomura, K., Antoch, M. P., Yamazaki, S., Zemenides, P. D., Ralph, M. R., . . . Takahashi, J. S. (2000, April 21). Positional syntenic cloning and functional characterization of the mammalian circadian mutation tau. Science, 288, 483-491. doi:10.1126/science.288 .5465 .483

Lyons, L. C. (2011). Critical role of the circadian clock in memory formation: Lessons from Aplysia. Frontiers in Molecular Neuroscience, 4, 52. doi:10.3389/fnmol.2011.00052

Maggio, N., \& Segal, M. (2010). Corticosteroid regulation of synaptic plasticity in the hippocampus. TheScientificWorldJournal, 10, 462-469. doi:10.1100/tsw.2010.48

Malenka, R. C. (2003). Synaptic plasticity and AMPA receptor trafficking. Annals of the New York Academy of Sciences, 1003, 1-11. doi:10.1196/ annals. 1300.001

Manda, K., \& Reiter, R. J. (2010). Melatonin maintains adult hippocampal neurogenesis and cognitive functions after irradiation. Progress in Neurobiology, 90, 60-68. doi:10.1016/j.pneurobio.2009.10.019
Marchant, E. G., \& Mistlberger, R. E. (1997). Anticipation and entrainment to feeding time in intact and SCN-ablated C57BL/6j mice. Brain Research, 765, 273-283. doi:10.1016/S0006-8993(97)00571-4

Maren, S., Aharonov, G., \& Fanselow, M. S. (1997). Neurotoxic lesions of the dorsal hippocampus and Pavlovian fear conditioning in rats. Behavioural Brain Research, 88, 261-274. doi:10.1016/S01664328(97)00088-0

Martin, S. J., Grimwood, P. D., \& Morris, R. G. (2000). Synaptic plasticity and memory: An evaluation of the hypothesis. Annual Review of Neuroscience, 23, 649-711. doi:10.1146/annurev.neuro.23.1.649

Martinez, J. L., Jr., \& Derrick, B. E. (1996). Long-term potentiation and learning. Апnиal Review of Psychology, 47, 173-203. doi:10.1146/ annurev.psych.47.1.173

Masri, S., \& Sassone-Corsi, P. (2010). Plasticity and specificity of the circadian epigenome. Nature Neuroscience, 13, 1324-1329. doi: $10.1038 / \mathrm{nn} .2668$

Matsuo, T., Yamaguchi, S., Mitsui, S., Emi, A., Shimoda, F., \& Okamura H. (2003, October 10). Control mechanism of the circadian clock for timing of cell division in vivo. Science, 302, 255-259. doi:10.1126/ science. 1086271

McDonald, R. J., Hong, N. S., Ray, C., \& Ralph, M. R. (2002). No time of day modulation or time stamp on multiple memory tasks in rats. Learning and Motivation, 33, 230-252. doi:10.1006/lmot.2001.1111

McDonald, R. J., Zelinski, E. L., Keeley, R. J., Sutherland, D., Fehr, L., \& Hong, N. S. (2013). Multiple effects of circadian dysfunction induced by photoperiod shifts: Alterations in context memory and food metabolism in the same subjects. Physiology \& Behavior, 118, 14-24. doi:10.1016/ j.physbeh.2013.04.010

Michán, S., Li, Y., Chou, M. M.-H., Parrella, E., Ge, H., Long, J. M., . . . Longo, V. D. (2010). SIRT1 is essential for normal cognitive function and synaptic plasticity. The Journal of Neuroscience: The Official Journal of the Society for Neuroscience, 30, 9695-9707. doi:10.1523/ JNEUROSCI.0027-10.2010

Miller, B. H., McDearmon, E. L., Panda, S., Hayes, K. R., Zhang, J., Andrews, J. L., . . . Takahashi, J. S. (2007). Circadian and CLOCKcontrolled regulation of the mouse transcriptome and cell proliferation. PNAS Proceedings of the National Academy of Sciences of the United States of America, 104, 3342-3347. doi:10.1073/pnas.0611724104

Mirescu, C., \& Gould, E. (2006). Stress and adult neurogenesis. Hippocampus, 16, 233-238. doi:10.1002/hipo.20155

Mirescu, C., Peters, J. D., Noiman, L., \& Gould, E. (2006). Sleep deprivation inhibits adult neurogenesis in the hippocampus by elevating glucocorticoids. PNAS Proceedings of the National Academy of Sciences of the United States of America, 103, 19170-19175. doi:10.1073/pnas .0608644103

Mistlberger, R. E. (1992). Anticipatory activity rhythms under daily schedules of water access in the rat. Journal of Biological Rhythms, 7 149-160. doi:10.1177/074873049200700206

Mistlberger, R. E. (1993). Circadian properties of anticipatory activity to restricted water access in suprachiasmatic-ablated hamsters. The American Journal of Physiology, 264, R22-R29.

Mistlberger, R. E. (2011). Neurobiology of food anticipatory circadian rhythms. Physiology \& Behavior, 104, 535-545. doi:10.1016/j.physbeh 2011.04 .015

Mistlberger, R. E., de Groot, M. H., Bossert, J. M., \& Marchant, E. G. (1996). Discrimination of circadian phase in intact and suprachiasmatic nuclei-ablated rats. Brain Research, 739, 12-18. doi:10.1016/S00068993(96)00466-0

Mohawk, J. A., \& Takahashi, J. S. (2011). Cell autonomy and synchrony of suprachiasmatic nucleus circadian oscillators. Trends in Neurosciences, 34, 349-358. doi:10.1016/j.tins.2011.05.003

Moore, R. Y., \& Eichler, V. B. (1972). Loss of a circadian adrenal corticosterone rhythm following suprachiasmatic lesions in the rat. Brain Research, 42, 201-206. doi:10.1016/0006-8993(72)90054-6 
Mueller, A. D., Mear, R. J., \& Mistlberger, R. E. (2011). Inhibition of hippocampal neurogenesis by sleep deprivation is independent of circadian disruption and melatonin suppression. Neuroscience, 193, 170181. doi:10.1016/j.neuroscience.2011.07.019

Mueller, A. D., Pollock, M. S., Lieblich, S. E., Epp, J. R., Galea, L. A. M., \& Mistlberger, R. E. (2008). Sleep deprivation can inhibit adult hippocampal neurogenesis independent of adrenal stress hormones. American Journal of Physiology: Regulatory, Integrative and Comparative Physiology, 294, R1693-R1703. doi:10.1152/ajpregu.00858.2007

Mulder, C. K., Gerkema, M. P., \& Van der Zee, E. A. (2013). Circadian clocks and memory: Time-place learning. Frontiers in Molecular Neuroscience, 6, 8. doi:10.3389/fnmol.2013.00008

Nader, N., Chrousos, G. P., \& Kino, T. (2009). Circadian rhythm transcription factor CLOCK regulates the transcriptional activity of the glucocorticoid receptor by acetylating its hinge region lysine cluster: Potential physiological implications. FASEB Journal: Official Publication of the Federation of American Societies for Experimental Biology, 23, 1572-1583. doi:10.1096/fj.08-117697

Nakahata, Y., Kaluzova, M., Grimaldi, B., Sahar, S., Hirayama, J., Chen, D., . . Sassone-Corsi, P. (2008). The NAD+-dependent deacetylase SIRT1 modulates CLOCK-mediated chromatin remodeling and circadian control. Cell, 134, 329-340. doi:10.1016/j.cell.2008.07.002

Naruse, Y., Oh-hashi, K., Iijima, N., Naruse, M., Yoshioka, H., \& Tanaka, M. (2004). Circadian and light-induced transcription of clock gene Per1 depends on histone acetylation and deacetylation. Molecular and Cellular Biology, 24, 6278-6287. doi:10.1128/MCB.24.14.6278-6287 .2004

Nishikawa, Y., Shibata, S., \& Watanabe, S. (1995). Circadian changes in long-term potentiation of rat suprachiasmatic field potentials elicited by optic nerve stimulation in vitro. Brain Research, 695, 158-162. doi: 10.1016/0006-8993(95)00717-5

Obrietan, K., Impey, S., \& Storm, D. R. (1998). Light and circadian rhythmicity regulate MAP kinase activation in the suprachiasmatic nuclei. Nature Neuroscience, 1, 693-700. doi:10.1038/3695

Ouyang, Y., Andersson, C. R., Kondo, T., Golden, S. S., \& Johnson, C. H. (1998). Resonating circadian clocks enhance fitness in cyanobacteria. PNAS Proceedings of the National Academy of Sciences of the United States of America, 95, 8660-8664. doi:10.1073/pnas.95.15.8660

Pagano, R. R., \& Lovely, R. H. (1972). Diurnal cycle and ACTH facilitation of shuttlebox avoidance. Physiology \& Behavior, 8, 721-723. doi:10.1016/0031-9384(72)90102-3

Perez-Cruz, C., Simon, M., Flügge, G., Fuchs, E., \& Czéh, B. (2009). Diurnal rhythm and stress regulate dendritic architecture and spine density of pyramidal neurons in the rat infralimbic cortex. Behavioural Brain Research, 205, 406-413. doi:10.1016/j.bbr.2009.07.021

Phan, T. X., Phan, T. H., Chan, G. C.-K., Sindreu, C. B., Eckel-Mahan, K. L., \& Storm, D. R. (2011). The diurnal oscillation of MAP (mitogenactivated protein) kinase and adenylyl cyclase activities in the hippocampus depends on the suprachiasmatic nucleus. The Journal of Neuroscience: The Official Journal of the Society for Neuroscience, 31, 10640-10647. doi:10.1523/JNEUROSCI.6535-10.2011

Pittendrigh, C. S., \& Minis, D. H. (1972). Circadian Systems: Longevity as a Function of Circadian Resonance in Drosophila melanogaster. PNAS Proceedings of the National Academy of Sciences of the United States of America, 69, 1537-1539. doi:10.1073/pnas.69.6.1537

Pugh, C. R., Tremblay, D., Fleshner, M., \& Rudy, J. W. (1997). A selective role for corticosterone in contextual-fear conditioning. Behavioral Neuroscience, 111, 503-511. doi:10.1037/0735-7044.111.3.503

Raghavan, A. V., Horowitz, J. M., \& Fuller, C. A. (1999). Diurnal modulation of long-term potentiation in the hamster hippocampal slice. Brain Research, 833, 311-314. doi:10.1016/S0006-8993(99)01523-1

Ralph, M. R., Ko, C. H., Antoniadis, E. A., Seco, P., Irani, F., Presta, C., \& McDonald, R. J. (2002). The significance of circadian phase for performance on a reward-based learning task in hamsters. Behavioural Brain Research, 136, 179-184. doi:10.1016/S0166-4328(02)00131-6

Ramírez-Rodríguez, G., Klempin, F., Babu, H., Benítez-King, G., \& Kempermann, G. (2009). Melatonin modulates cell survival of new neurons in the hippocampus of adult mice. Neuropsychopharmacology: Official Publication of the American College of Neuropsychopharmacology, 34, 2180-2191. doi:10.1038/npp.2009.46

Ramirez-Rodriguez, G., Ortíz-López, L., Domínguez-Alonso, A., BenítezKing, G. A., \& Kempermann, G. (2011). Chronic treatment with melatonin stimulates dendrite maturation and complexity in adult hippocampal neurogenesis of mice. Journal of Pineal Research: Molecular, Biological, Physiological and Clinical Aspects of Melatonin, 50, 29-37. doi:10.1111/j.1600-079X.2010.00802.x

Rao, M. S., \& Shetty, A. K. (2004). Efficacy of doublecortin as a marker to analyse the absolute number and dendritic growth of newly generated neurons in the adult dentate gyrus. The European Journal of Neuroscience, 19, 234-246. doi:10.1111/j.0953-816X.2003.03123.x

Reddy, A. B., Field, M. D., Maywood, E. S., \& Hastings, M. H. (2002). Differential resynchronisation of circadian clock gene expression within the suprachiasmatic nuclei of mice subjected to experimental jet lag. The Journal of Neuroscience: The Official Journal of the Society for Neuroscience, 22, 7326-7330.

Reebs, S. G. (1996). Time-place learning in golden shiners (Pisces: Cyprinidae). Behavioural Processes, 36, 253-262. doi:10.1016/03766357(96)88023-5

Rennie, K., De Butte, M., \& Pappas, B. A. (2009). Melatonin promotes neurogenesis in dentate gyrus in the pinealectomized rat. Journal of Pineal Research: Molecular, Biological, Physiological and Clinical Aspects of Melatonin, 47, 313-317. doi:10.1111/j.1600-079X.2009 .00716. $\mathrm{x}$

Ripperger, J. A., \& Schibler, U. (2006). Rhythmic CLOCK-BMAL1 binding to multiple E-box motifs drives circadian Dbp transcription and chromatin transitions. Nature Genetics, 38, 369-374. doi:10.1038/ ng 1738

Rossi, C., Angelucci, A., Costantin, L., Braschi, C., Mazzantini, M., Babbini, F., . . . Caleo, M. (2006). Brain-derived neurotrophic factor (BDNF) is required for the enhancement of hippocampal neurogenesis following environmental enrichment. European Journal of Neuroscience, 24, 1850-1856. doi:10.1111/j.1460-9568.2006.05059.x

Ruby, N. F., Fernandez, F., Garrett, A., Klima, J., Zhang, P., Sapolsky, R., \& Heller, H. C. (2013). Spatial memory and long-term object recognition are impaired by circadian arrhythmia and restored by the GABAAAntagonist pentylenetetrazole. PLoS One, 8, e72433. doi: 10.1371/journal.pone.0072433

Ruby, N. F., Hwang, C. E., Wessells, C., Fernandez, F., Zhang, P., Sapolsky, R., \& Heller, H. C. (2008). Hippocampal-dependent learning requires a functional circadian system. PNAS Proceedings of the National Academy of Sciences of the United States of America, 105, 15593-15598. doi:10.1073/pnas.0808259105

Rudy, J. W., \& Pugh, C. R. (1998). Time of conditioning selectively influences contextual fear conditioning: Further support for a multiplememory systems view of fear conditioning. Journal of Experimental Psychology: Animal Behavior Processes, 24, 316-324. doi:10.1037/ 0097-7403.24.3.316

Saha, A., Wittmeyer, J., \& Cairns, B. R. (2006). Chromatin remodelling: The industrial revolution of DNA around histones. Nature Reviews Molecular Cell Biology, 7, 437-447. doi:10.1038/nrm1945

Sahar, S., \& Sassone-Corsi, P. (2012). Circadian rhythms and memory formation: Regulation by chromatin remodeling. Frontiers in Molecular Neuroscience, 5, 37. doi:10.3389/fnmol.2012.00037

Sairanen, M., Lucas, G., Ernfors, P., Castrén, M., \& Castrén, E. (2005). Brain-derived neurotrophic factor and antidepressant drugs have different but coordinated effects on neuronal turnover, proliferation, and survival in the adult dentate gyrus. The Journal of Neuroscience: The 
Official Journal of the Society for Neuroscience, 25, 1089-1094. doi: 10.1523/JNEUROSCI.3741-04.2005

Sanada, K., Okano, T., \& Fukada, Y. (2001). Mitogen-activated protein kinase phosphorylates and negatively regulates basic helix-loop-helixPAS transcription factor BMAL1. The Journal of Biological Chemistry, 277, 267-271. doi:10.1074/jbc.M107850200

Saxe, M. D., Battaglia, F., Wang, J.-W., Malleret, G., David, D. J., Monckton, J. E., . . . Drew, M. R. (2006). Ablation of hippocampal neurogenesis impairs contextual fear conditioning and synaptic plasticity in the dentate gyrus. PNAS Proceedings of the National Academy of Sciences of the United States of America, 103, 17501-17506. doi: 10.1073/pnas.0607207103

Schibler, U., Ripperger, J., \& Brown, S. A. (2003). Peripheral circadian oscillators in mammals: Time and food. Journal of Biological Rhythms, 18, 250-260. doi:10.1177/0748730403018003007

Schoenfeld, T. J., \& Gould, E. (2012). Stress, stress hormones, and adult neurogenesis. Experimental Neurology, 233, 12-21. doi:10.1016/j .expneurol.2011.01.008

Scott, R., Bourtchuladze, R., Gossweiler, S., Dubnau, J., \& Tully, T. (2002). CREB and the discovery of cognitive enhancers. Journal of Molecular Neuroscience: MN, 19, 171-177. doi:10.1007/s12031-0020029-z

Segall, L. A., Milet, A., Tronche, F., \& Amir, S. (2009). Brain glucocorticoid receptors are necessary for the rhythmic expression of the clock protein, PERIOD2, in the central extended amygdala in mice. Neuroscience Letters, 457, 58-60. doi:10.1016/j.neulet.2009.03.083

Segall, L. A., Perrin, J. S., Walker, C.-D., Stewart, J., \& Amir, S. (2006). Glucocorticoid rhythms control the rhythm of expression of the clock protein, Period2, in oval nucleus of the bed nucleus of the stria terminalis and central nucleus of the amygdala in rats. Neuroscience, 140, 753757. doi:10.1016/j.neuroscience.2006.03.037

Sei, H., Fujihara, H., Ueta, Y., Morita, K., Kitahama, K., \& Morita, Y. (2003). Single eight-hour shift of light-dark cycle increases brainderived neurotrophic factor protein levels in the rat hippocampus. Life Sciences, 73, 53-59. doi:10.1016/S0024-3205(03)00251-0

Sei, H., Saitoh, D., Yamamoto, K., Morita, K., \& Morita, Y. (2000). Differential effect of short-term REM sleep deprivation on NGF and BDNF protein levels in the rat brain. Brain Research, 877, 387-390. doi:10.1016/S0006-8993(00)02708-6

Sharma, V. K. (2003). Adaptive significance of circadian clocks. Chronobiology International, 20, 901-919. doi:10.1081/CBI-120026099

Shors, T. J., Miesegaes, G., Beylin, A., Zhao, M., Rydel, T., \& Gould, E. (2001, March 15). Neurogenesis in the adult is involved in the formation of trace memories. Nature, 410, 372-376. doi:10.1038/35066584

Shors, T. J., Townsend, D. A., Zhao, M., Kozorovitskiy, Y., \& Gould, E. (2002). Neurogenesis may relate to some but not all types of hippocampal-dependent learning. Hippocampus, 12, 578-584. doi: 10.1002/hipo.10103

Shuboni, D., \& Yan, L. (2010). Nighttime dim light exposure alters the responses of the circadian system. Neuroscience, 170, 1172-1178. doi: 10.1016/j.neuroscience.2010.08.009

Silva, A. J. (2003). Molecular and cellular cognitive studies of the role of synaptic plasticity in memory. Journal of Neurobiology, 54, 224-237. doi:10.1002/neu.10169

Silva, A. J., Kogan, J. H., Frankland, P. W., \& Kida, S. (1998). CREB and memory. Annual Review of Neuroscience, 21, 127-148. doi:10.1146/ annurev.neuro.21.1.127

Smarr, B. L., Gile, J. J., \& de la Iglesia, H. O. (2013). Oestrogenindependent circadian clock gene expression in the anteroventral periventricular nucleus in female rats: Possible role as an integrator for circadian and ovarian signals timing the LH surge. Journal of Neuroendocrinology, 25, 1273-1279. doi:10.1111/jne.12104
Smarr, B. L., Schwartz, M. D., Wotus, C., \& de la Iglesia, H. O. (2013). Re-examining "temporal niche". Integrative and Comparative Biology, 53, 165-174. doi:10.1093/icb/ict055

Smith, J. M., Hechtman, A., \& Swann, J. (2010). Fluctuations in cellular proliferation across the light/dark cycle in the subgranular zone of the dentate gyrus in the adult male Syrian hamster. Neuroscience Letters, 473, 192-195. doi:10.1016/j.neulet.2010.02.039

Sompol, P., Liu, X., Baba, K., Paul, K. N., Tosini, G., Iuvone, P. M., \& Ye, K. (2011). N-acetylserotonin promotes hippocampal neuroprogenitor cell proliferation in sleep-deprived mice. PNAS Proceedings of the National Academy of Sciences of the United States of America, 108, 8844-8849. doi:10.1073/pnas.1105114108

Sportiche, N., Suntsova, N., Methippara, M., Bashir, T., Mitrani, B. Szymusiak, R., \& McGinty, D. (2010). Sustained sleep fragmentation results in delayed changes in hippocampal-dependent cognitive function associated with reduced dentate gyrus neurogenesis. Neuroscience, 170, 247-258. doi:10.1016/j.neuroscience.2010.06.038

Stephan, F. K., \& Kovacevic, N. S. (1978). Multiple retention deficit in passive avoidance in rats is eliminated by suprachiasmatic lesions. Behavioral Biology, 22, 456-462. doi:10.1016/S0091-6773(78)92565-8

Stephan, F. K., Swann, J. M., \& Sisk, C. L. (1979). Entrainment of circadian rhythms by feeding schedules in rats with suprachiasmatic lesions. Behavioral \& Neural Biology, 25, 545-554. doi:10.1016/S01631047(79)90332-7

Stephan, F. K., \& Zucker, I. (1972). Circadian rhythms in drinking behavior and locomotor activity of rats are eliminated by hypothalamic lesions. PNAS Proceedings of the National Academy of Sciences of the United States of America, 69, 1583-1586. doi:10.1073/pnas.69.6.1583

Stroebel, C. F. (1967). Behavioral aspects of circadian rhythms. Proceedings of the Annual Meeting of the American Psychopathological Association, $55,158-172$.

Sweatt, J. D. (2001). Memory mechanisms: The yin and yang of protein phosphorylation. Current Biology: CB, 11, R391-R394.

Sweatt, J. D. (2009). Experience-dependent epigenetic modifications in the central nervous system. Biological Psychiatry, 65, 191-197. doi 10.1016/j.biopsych.2008.09.002

Taliaz, D., Stall, N., Dar, D. E., \& Zangen, A. (2010). Knockdown of brain-derived neurotrophic factor in specific brain sites precipitates behaviors associated with depression and reduces neurogenesis. Molec ular Psychiatry, 15, 80-92. doi:10.1038/mp.2009.67

Tamai, S., Sanada, K., \& Fukada, Y. (2008). Time-of-day-dependent enhancement of adult neurogenesis in the hippocampus. PLoS One, 3 , e3835. doi:10.1371/journal.pone.0003835

Tapp, W. N., \& Holloway, F. A. (1981, March 6). Phase shifting circadian rhythms produces retrograde amnesia. Science, 211, 1056-1058. doi 10.1126/science.7193351

Ternes, J. W. (1976). Resistance to extinction of a learned taste aversion varies with time of conditioning. Animal Learning \& Behavior, 4 317-321. doi:10.3758/BF03214057

Tischkau, S. A., Gallman, E. A., Buchanan, G. F., \& Gillette, M. U. (2000). Differential cAMP gating of glutamatergic signaling regulates long-term state changes in the suprachiasmatic circadian clock. The Journal of Neuroscience: The Official Journal of the Society for Neuroscience, 20 $7830-7837$

Tosini, G., Ye, K., \& Iuvone, P. M. (2012). N-acetylserotonin: Neuroprotection, neurogenesis, and the sleepy brain. The Neuroscientist: A Review Journal Bringing Neurobiology, Neurology and Psychiatry, 18 645-653. doi:10.1177/1073858412446634

Travnickova-Bendova, Z., Cermakian, N., Reppert, S. M., \& SassoneCorsi, P. (2002). Bimodal regulation of mPeriod promoters by CREBdependent signaling and CLOCK/BMAL1 activity. PNAS Proceedings of the National Academy of Sciences of the United States of America, 99, 7728-7733. doi:10.1073/pnas.102075599 
Tronel, S., Fabre, A., Charrier, V., Oliet, S. H. R., Gage, F. H., \& Abrous, D. N. (2010). Spatial learning sculpts the dendritic arbor of adult-born hippocampal neurons. PNAS Proceedings of the National Academy of Sciences of the United States of America, 107, 7963-7968. doi:10.1073/ pnas.0914613107

Ueda, H. R., Hayashi, S., Chen, W., Sano, M., Machida, M., Shigeyoshi, Y., . . Hashimoto, S. (2005). System-level identification of transcriptional circuits underlying mammalian circadian clocks. Nature Genetics, 37, 187-192. doi:10.1038/ng1504

Valentinuzzi, V. S., Kolker, D. E., Vitaterna, M. H., Ferrari, E. A. M., Takahashi, J. S., \& Turek, F. W. (2001). Effect of circadian phase on context and cued fear conditioning in C57BL/6J mice. Animal Learning \& Behavior, 29, 133-142. doi:10.3758/BF03192822

Valentinuzzi, V. S., Menna-Barreto, L., \& Xavier, G. F. (2004). Effect of circadian phase on performance of rats in the Morris water maze task. Journal of Biological Rhythms, 19, 312-324. doi:10.1177/ 0748730404265688

Valnegri, P., Khelfaoui, M., Dorseuil, O., Bassani, S., Lagneaux, C., Gianfelice, A., .. . Passafaro, M. (2011). A circadian clock in hippocampus is regulated by interaction between oligophrenin-1 and Rev-erb $\alpha$. Nature Neuroscience, 14, 1293-1301. doi:10.1038/nn.2911

van der Borght, K., Ferrari, F., Klauke, K., Roman, V., Havekes, R., Sgoifo, A., . . Meerlo, P. (2006). Hippocampal cell proliferation across the day: Increase by running wheel activity, but no effect of sleep and wakefulness. Behavioural Brain Research, 167, 36-41. doi:10.1016/j .bbr.2005.08.012

van der Borght, K., Meerlo, P., Luiten, P. G. M., Eggen, B. J. L., \& Van der Zee, E. A. (2005). Effects of active shock avoidance learning on hippocampal neurogenesis and plasma levels of corticosterone. Behavioural Brain Research, 157, 23-30. doi:10.1016/j.bbr.2004.06.004

Wakamatsu, H., Yoshinobu, Y., Aida, R., Moriya, T., Akiyama, M., \& Shibata, S. (2001). Restricted-feeding-induced anticipatory activity rhythm is associated with a phase-shift of the expression of mPer1 and mPer2 mRNA in the cerebral cortex and hippocampus but not in the suprachiasmatic nucleus of mice. European Journal of Neuroscience, 13, 1190-1196. doi:10.1046/j.0953-816x.2001.01483.x

Wang, G.-Q., Du, Y.-Z., \& Tong, J. (2007). Daily oscillation and photoresponses of clock gene, Clock, and clock-associated gene, arylalkylamine $\mathrm{N}$-acetyltransferase gene transcriptions in the rat pineal gland. Chronobiology International, 24, 9-20. doi:10.1080/ 07420520601139821

Wang, H., Ferguson, G. D., Pineda, V. V., Cundiff, P. E., \& Storm, D. R. (2004). Overexpression of type- 1 adenylyl cyclase in mouse forebrain enhances recognition memory and LTP. Nature Neuroscience, 7, 635642. doi: $10.1038 / \mathrm{nn} 1248$

Wang, L. M., Dragich, J. M., Kudo, T., Odom, I. H., Welsh, D. K., O’Dell, T. J., \& Colwell, C. S. (2009). Expression of the circadian clock gene
Period2 in the hippocampus: Possible implications for synaptic plasticity and learned behaviour. ASN Neuro, 1, e00012. doi:10.1042/ AN20090020

Wansley, R. A., \& Holloway, F. A. (1975). Multiple retention deficits following one-trial appetitive training. Behavioral Biology, 14, 135-149. doi:10.1016/S0091-6773(75)90135-2

Wansley, R. A., \& Holloway, F. A. (1976). Oscillations in retention performance after passive avoidance training. Learning and Motivation, 7, 296-302. doi:10.1016/0023-9690(76)90037-0

Watanabe, Y., Gould, E., \& McEwen, B. S. (1992). Stress induces atrophy of apical dendrites of hippocampal CA3 pyramidal neurons. Brain Research, 588, 341-345. doi:10.1016/0006-8993(92)91597-8

Weinert, D., Eimert, H., Erkert, H. G., \& Schneyer, U. (1994). Resynchronization of the circadian corticosterone rhythm after a light/dark shift in juvenile and adult mice. Chronobiology International, 11, 222-231. doi:10.3109/07420529409067791

Welsh, D. K., Yoo, S.-H., Liu, A. C., Takahashi, J. S., \& Kay, S. A. (2004) Bioluminescence imaging of individual fibroblasts reveals persistent, independently phased circadian rhythms of clock gene expression. Current Biology: CB, 14, 2289-2295. doi:10.1016/j.cub.2004.11.057

West, M. O., \& Deadwyler, S. A. (1980). Circadian modulation of granule cell response to perforant path synaptic input in the rat. Neuroscience, 5, 1597-1602. doi:10.1016/0306-4522(80)90023-8

Woolley, C. S., Gould, E., \& McEwen, B. S. (1990). Exposure to excess glucocorticoids alters dendritic morphology of adult hippocampal pyramidal neurons. Brain Research, 531, 225-231. doi:10.1016/00068993(90)90778-A

Wotus, C., Lilley, T. R., Neal, A. S., Suleiman, N. L., Schmuck, S. C., Smarr, B. L., . . . de la Iglesia, H. O. (2013). Forced desynchrony reveals independent contributions of suprachiasmatic oscillators to the daily plasma corticosterone rhythm in male rats. PLoS One, 8, e68793. doi 10.1371/journal.pone.0068793

Wyse, C. A., \& Coogan, A. N. (2010). Impact of aging on diurnal expression patterns of CLOCK and BMAL1 in the mouse brain. Brain Research, 1337, 21-31. doi:10.1016/j.brainres.2010.03.113

Wyse, C. A., Coogan, A. N., Selman, C., Hazlerigg, D. G., \& Speakman, J. R. (2010). Association between mammalian lifespan and circadian free-running period: The circadian resonance hypothesis revisited. Biology Letters, 6, 696-698. doi:10.1098/rsb1.2010.0152

Yamazaki, S., Numano, R., Abe, M., Hida, A., Takahashi, R., Ueda, M., . . . Tei, H. (2000, April 28). Resetting central and peripheral circadian oscillators in transgenic rats. Science, 288, 682-685. doi:10.1126/ science. 288.5466 .682

Received October 29, 2013

Revision received January 7, 2014 Accepted January 8, 2014 